\title{
Arquitectura estratigráfica, ambientes de depósito y geocronología de la Formación Olinalá (Pérmico tardío), noreste de Guerrero, México
}

\section{Edgar Juárez-Arriaga ${ }^{1, *}$ y Gustavo Murillo-Muñetón ${ }^{2}$}

\author{
${ }^{1}$ Centro de Geociencias, Universidad Nacional Autónoma de México, \\ Boulevard Juriquilla 3001, C.P. 76230, Querétaro, México. \\ ${ }^{2}$ Instituto Mexicano del Petróleo, Dirección de Exploración y Producción, \\ Eje Central Lázaro Cárdenas No. 152, C.P. 07730, Ciudad de México, México. \\ *ejarriaga@geociencias.unam.mx
}

\section{RESUMEN}

La Formación Olinalá representa una sucesión sedimentaria pérmica marino-continental de $\sim 860 \mathrm{~m}$ de espesor, excepcionalmente expuesta en el noreste del estado de Guerrero, en el sur de México. La arquitectura estratigráfica de esta unidad sugiere un sistema de depósito de plataforma tipo rampa homoclinal con sedimentación mixta (terrígena-carbonatada). El análisis $\mathrm{U}-\mathrm{Pb}$ en granos de circón detrítico obtenidos de dos muestras colectados cerca de la base de la Formación Olinalá permitió determinar una edad máxima de depósito de $268 \pm 5 \mathrm{Ma}$, misma que es consistente con la edad de Wordiano previamente determinada a partir de amonoideos colectados en la base de esta unidad. Esta sucesión sedimentaria contiene una amplia diversidad de facies terrígenas continentales cuyo arreglo arquitectural sugiere el desarrollo de un valle de incisión fluvial de al menos $130 \mathrm{~m}$ de profundidad. Por otro lado, las facies terrígenas y carbonatadas marinas sugieren el desarrollo de un sistema de rampa en aguas cálidas bajo condiciones marinas normales. La sucesión de ambientes de depósito en la Formación Olinalá a través del tiempo permite deducir variaciones en el nivel del mar de distinta magnitud que controlaron, en parte, su evolución sedimentaria.

Palabras clave: Pérmico; rampa homoclinal; facies sedimentarias; Formación Olinalá; geocronología U-Pb; valle de incisión fluvial.

\section{ABSTRACT}

The Olinalá Formation is a marine-continental Permian sedimentary succession of $\sim 860 \mathrm{~m}$ thick, which is exceptionally exposed in the northeast of the Guerrero state, in southern Mexico. The depositional architecture of this sedimentary succession indicates a mixed carbonatesiliciclastic homoclinal ramp system. The U-Pb ages of detrital zircon grains set from two basal sandstones of the Olinalá Formation yielded a weighted mean maximum deposit age of $268 \pm 5 \mathrm{Ma}$, which agrees with a Wordian biostratigraphic age based on ammonoids collected at its base. Wide continental siliciclastic facies diversity was identified in this sedimentary succession that represents a prominent fluvial incision valley of $130 \mathrm{~m}$ depth, at least. Instead, the siliciclastic and carbonate marine facies indicate a ramp system developed in warm waters and normal salinity conditions. The superposition of different environments in the Olinala Formation through time allows us to deduce sea-level changes of a different magnitude, which partly controlled the sedimentary evolution of this unit.

Key words: Permian; homoclinal ramp; sedimentary facies; Olinalá Formation; U-Pb geochronology; fluvial incision valley.

\section{INTRODUCCIÓN}

La Formación Olinalá es una sucesión sedimentaria mixta, terrígena-carbonatada, expuesta en la región noreste del estado de Guerrero y representa parte de los depósitos pérmicos marino-continentales más australes en América del Norte. La Formación Olinalá es una sucesión excepcionalmente expuesta en el sur de México (Flores de Dios y Buitrón, 1982; Corona-Esquivel, 1983; Figura 1). Esta unidad litoestratigráfica es contemporánea a las formaciones Grayburg, Queen, Seven Rivers, Yates, Tansill y la Caliza Capitan expuestas a lo largo del borde noroccidental de la cuenca de Delaware (Tait et al., 1962; Smith, 1974; Ward et al., 1986; Kerans et al., 1994; Mazzullo, 1999), así como a los depósitos de aguas profundas de la Formación Bell Canyon de esta misma cuenca (Silver y Todd, 1969; Kelley, 1971; Tinker, 1998). A pesar de que la Formación Olinalá ha sido afectada por procesos tectónicos es posible reconocer un registro estratigráfico continuo y bien conservado. Estas características hacen de la Formación Olinalá un modelo análogo ideal para mejorar la comprensión de los sistemas sedimentarios pérmicos en el sur del México y América del Norte.

Esta sucesión sedimentaria ha recibido dos nombres; por un lado Corona-Esquivel (1982) describe estas rocas denominándolas Formación Los Arcos y le asignó una edad de Pérmico superior. No obstante, el término Formación Olinalá, introducido por Flores de Dios y Buitrón (1982), es el más ampliamente utilizado en la literatura (e.g., Vachard et al., 1993, 2004; Buitrón et al., 1997, 2005; Flores de Dios et al., 2000; Silva-Pineda et al., 2003; Álvaro et al., 2007).

Estudios previos reconocen una amplia y compleja variedad de facies en la Formación Olinalá cuyas relaciones y significado no han quedado claramente establecidas. Este trabajo contribuye al conocimiento de este sistema pérmico con el aporte de nuevos datos estratigráficos, sedimentológicos y geocronológicos que permiten definir con mayor precisión el ambiente de depósito y edad de la Formación Olinalá. Para lograr dichas metas fueron medidas a detalle tres secciones estratigrá-

Juárez-Arriaga, E., Murillo-Muñetón, G., 2020, Arquitectura estratigráfica, ambientes de depósito y geocronología de la Formación Olinalá (Pérmico tardío), noreste de Guerrero, México: Revista Mexicana de Ciencias Geológicas, v. 37, núm. 3, p. 179-196. 


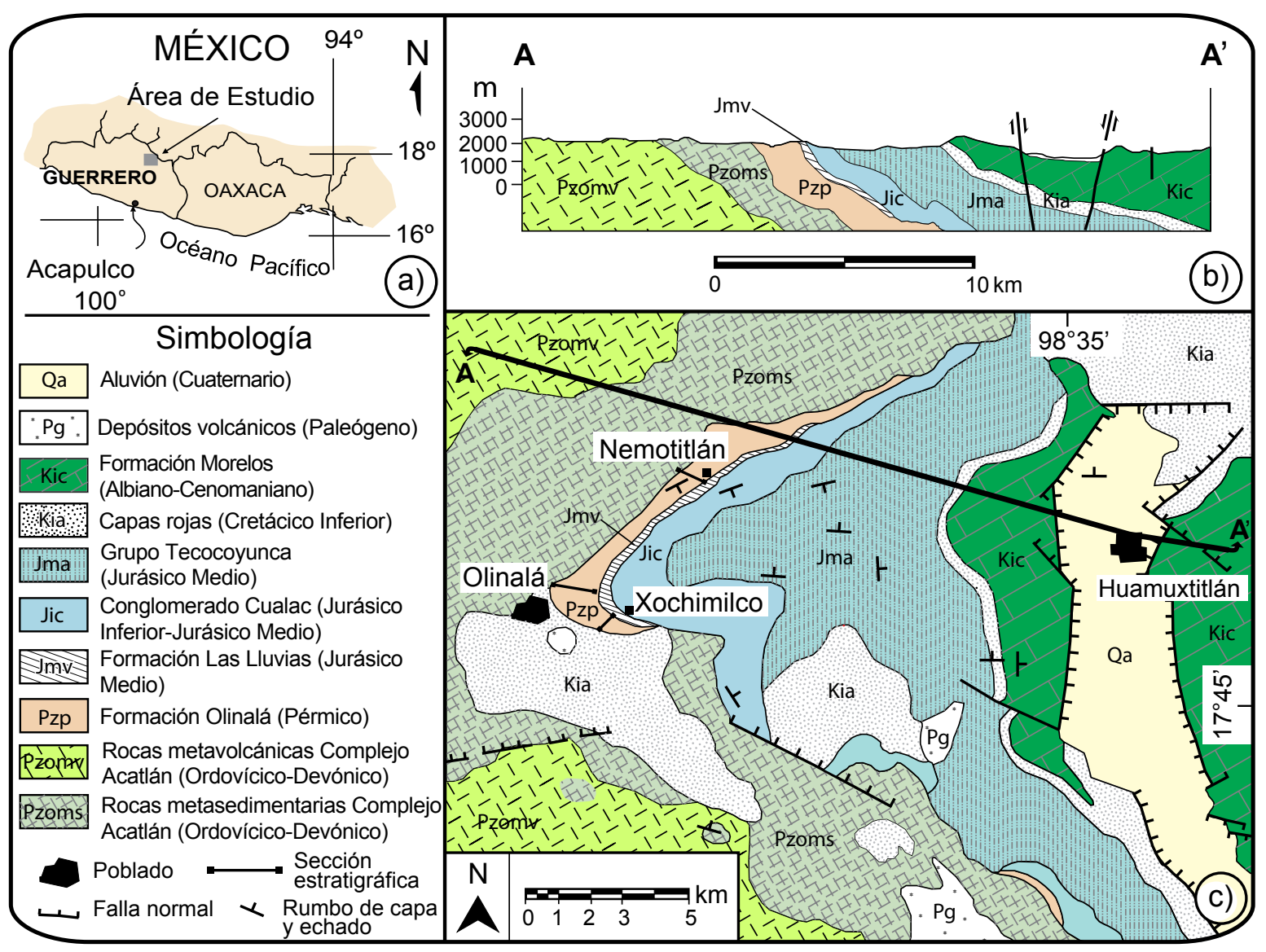

Figura 1. Área de estudio. (a) Ubicación de la región de la Montaña de Guerrero, noreste del estado de Guerrero. (b) Sección geológica A-A’. (c) Mapa geológico donde se muestran las principales unidades litoestratigráficas en el área de Olinalá (modificado de Campa et al., 1998); se muestra la ubicación de las secciones estudiadas en este trabajo: Nemotilán, Olinalá y Xochimilco.

ficas y se identificaron los diferentes tipos de litofacies, así como sus relaciones estratigráficas. Con base en esta información se propone un modelo de depósito para la Formación Olinalá y se calcula la edad máxima de depósito de la base de esta unidad con base en edades $\mathrm{U}-\mathrm{Pb}$ en granos de circón detrítico, esta última permite una mejor correlación con otras unidades pérmicas en México y América del Norte.

\section{MARCO GEOLÓGICO}

\section{Área de estudio y estratigrafía local}

El área de estudio se ubica $216 \mathrm{~km}$ al noreste de la Ciudad de Chilpancingo, en lo que se conoce como la Montaña de Guerrero, cuyo registro estratigráfico incluye rocas del Paleozoico inferior al Cenozoico (Figura 1). Esta región se encuentra en la Sierra Madre del Sur y se caracteriza por una topografía abrupta dominada por sierras y barrancos. La Montaña de Guerrero se encuentra dentro del terreno Mixteca (Campa y Coney, 1983), cuyo basamento está formado por rocas metamórficas paleozoicas del complejo Acatlán (Ortega-Gutiérrez et al., 1999; Sánchez-Zavala et al., 1999; Talavera-Mendoza et al., 2005). Las partes más elevadas de la región están coronadas por depósitos que corresponden al Conglomerado Cualac del Jurásico Inferior y Medio (Zepeda-Martínez et al., 2018), mientras que en las partes bajas afloran las rocas paleozoicas del Complejo Acatlán y la Formación Olinalá. En esta región hay zonas de relevo de falla de decenas de kilómetros y cuerpos intrusivos de edad incierta (Campa et al., 1998).
La Formación Olinalá sobreyace discordantemente al Complejo Acatlán (Corona-Esquivel, 1982, 1983; Flores de Dios y Buitrón, 1982; Vachard et al., 1993). Localmente, al noreste del poblado de Olinalá el contacto entre ambas unidades es por falla lateral, aparentemente derecha, con rumbo $\mathrm{N} 10^{\circ} \mathrm{E} 76^{\circ} \mathrm{SE}$ y una zona de cizalla de $12 \mathrm{~m}$. Al este del poblado de Nemotitlán, la Formación Olinalá es cubierta discordantemente por rocas piroclásticas de la Formación Las Lluvias de edad Jurásico Medio (Campa et al., 2004). A su vez, dicha unidad subyace discordantemente al Conglomerado Cualac de edad Jurásico Inferior-Medio (Erben, 1956; Jiménez-Rentería y Rueda-Gaxiola, 2002; Zepeda-Martínez et al., 2018). Esta sucesión sedimentaria subyace concordantemente al Grupo Tecocoyunca que incluye una sucesión sedimentaria terrígena continental a marina del Jurásico Medio (Guzmán, 1950; Erben, 1956; Quezada-Muñetón, 1970; Flores de Dios y Buitrón, 1982; Corona-Esquivel, 1982, 1983; Morán-Zenteno et al., 1993; García-Díaz, 2004). Finalmente, las unidades litoestratigráficas más jóvenes están representadas por depósitos terrígenos indiferenciados del Cretácico y Paleógeno (Flores de Dios y Buitrón, 1982).

\section{Generalidades sobre la Formación Olinalá}

La Formación Olinalá se encuentra bien expuesta al noreste del poblado homónimo, en el estado de Guerrero. Su localidad tipo está en la Cañada de Los Arcos (sección Olinalá en este trabajo) donde está constituida dominantemente por lutita y de manera subordinada por conglomerado y arenisca. Las capas de esta formación buzan regionalmente entre $59^{\circ}-76^{\circ}$ hacia el sureste (Figura 1 ). 
Informalmente se reconocen en la Formación Olinalá dos miembros siliciclásticos y un miembro carbonatado intermedio (Figura 2). En particular, las facies carbonatadas han sido interpretadas como depósitos de plataforma interna con parches y montículos arrecifales que gradan sección arriba a depósitos de margen de plataforma con bancos de arenas carbonatadas (Gutiérrez-Quinto, 2002). Estas facies también han sido consideradas parte de un sistema de rampa carbonatada, mientras que las facies terrígenas fueron interpretadas como parte de un sistema deltaico (Flores de Dios et al., 2000; SilvaPineda et al., 2003).

El contenido fósil en la base de la Formación Olinalá permite asignarle una edad de Wordiano(?)-Capitaneano (Vachard et al., 1993; 2004; González-Arreola et al., 1994; Silva-Pineda et al., 2003; EsquivelMacías et al., 2004). Sus fósiles se han comparado con el contenido de sección Xochimilco

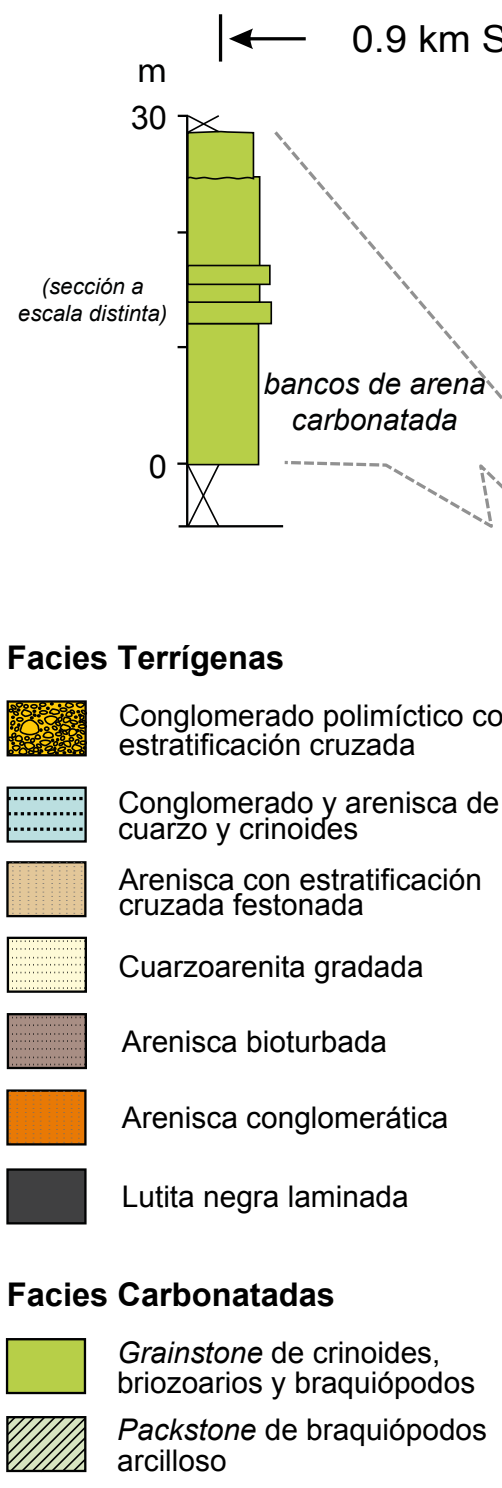

sección Olinalá

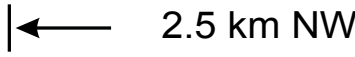

sección Nemotitlán

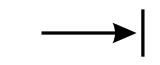

$\mathrm{m}$
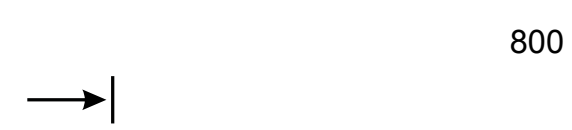

$\mathrm{m}$

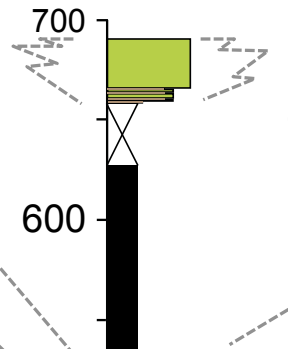

bancos de arena carbonatada

rampa externacuenca (offshore)
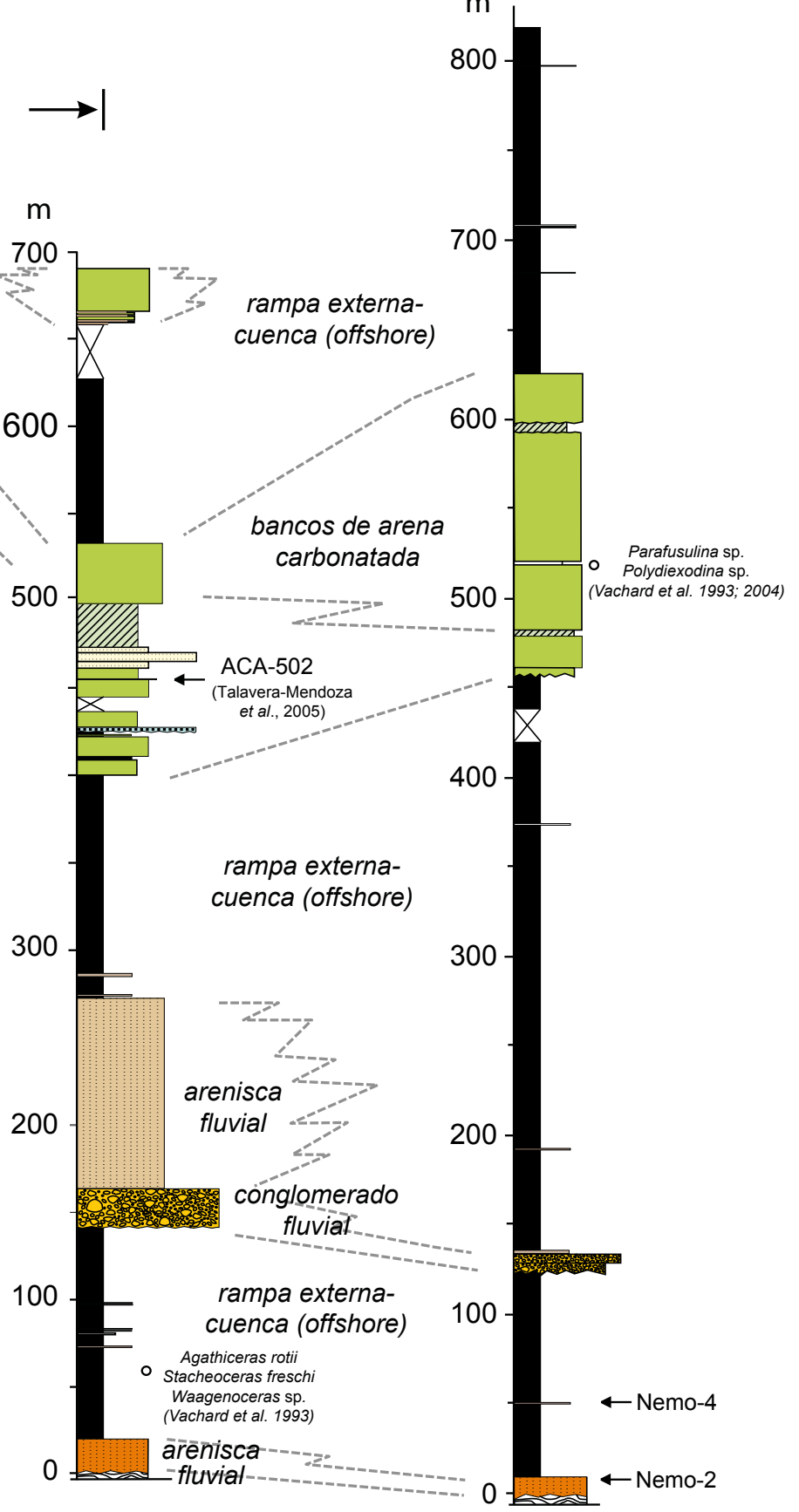

Figura 2. Secciones estratigráficas medidas de la Formación Olinalá. Se indica el ambiente de depósito inferido y la posición estratigráfica de las muestras usadas para el análisis geocronológico. La ubicación de las secciones medidas se indica en la Figura 1. El nivel estratigráfico de la muestra reportada por Talavera-Mendoza et al. (2005) y el de los fósiles colectados por Vachard et al., (1993; 2004) son aproximados. 
otras unidades litoestratigráficas del sur de América del Norte, particularmente con las formaciones Tordillo, Palo Quemado y La Difunta del suroeste de Coahuila, en el norte de México (Silva-Pineda et al., 2003; Vachard et al., 1993; 2004), así como con unidades de la Serie Leonard de las Montañas Glass (González-Arreola et al., 1994), la Caliza Capitán (Vachard et al., 1993; 2004) y la Caliza Lamar (Bell Canyon) del este de Texas (Vachard et al., 1993; 2004; Silva-Pineda et al., 2003).

\section{Localización y espesor de las secciones estratigráficas Olinalá y Nemotitlán}

Las secciones Olinalá y Nemotitlán contienen el registro estratigráfico más completo de la Formación Olinalá. La primera se localiza al este del poblado de Olinalá, cuenta con un espesor de $\sim 690 \mathrm{~m}$ y representa los mejores afloramientos de las partes inferior y media de la formación. La segunda sección se ubica en los alrededores de la villa de Nemotitlán, aproximadamente $3 \mathrm{~km}$ al noreste de Olinalá (Figuras 1 y 2). Esta sección representa las mejores exposiciones de la porción superior de esta formación y tiene un espesor de alrededor de $860 \mathrm{~m}$. Los afloramientos en ambas secciones son relativamente continuos, ocasionalmente la medición se realizó en transectos separados entre sí por unos $300 \mathrm{~m}$ debido a que algunos afloramientos están cubiertos o son inaccesibles. La sección Xochimilco corresponde a una sucesión carbonatada de $26 \mathrm{~m}$ de espesor, se encuentra al este de Olinalá y representa la parte media de la unidad. Debido a su limitada exposición, esta sección constituye un marco de comparación y referencia para las facies carbonatadas presentes en las otras dos secciones.

\section{MÉTODOS}

Tres columnas estratigráficas fueron medidas y descritas a detalle con báculo de Jacob y nivel de Abney para definir la arquitectura estratigráfica de la Formación Olinalá. Cada sección fue descrita con énfasis en la litología, espesor, contenido fósil, estructuras sedimentarias, medición de paleocorrientes, así como el tipo y relación de contacto estratigráfico. Para determinar el ambiente de depósito, las litofacies continentales y sus asociaciones fueron dilucidadas bajo el esquema propuesto por Miall (2006). De igual manera, las facies marinas someras fueron interpretadas de acuerdo a los modelos de Ahr (1985) y Read (1985). Los datos de paleocorrientes fueron corregidos de acuerdo a Collinson et al. (2006). Se colectaron muestras de roca para su análisis petrográfico de afloramientos representativos para cada facies; cada muestra de arenisca fue clasificada de acuerdo al esquema propuesto por Folk (1974), mientras que las muestras de caliza se clasificaron de acuerdo al modelo de Dunham (1962). Las muestras de arenisca Nemo-2 y Nemo-4 fueron colectadas en la base de la Formación Olinalá para determinar la edad máxima de depósito. Un conjunto de 57 análisis U-Pb procedente de una muestra colectada por Talavera-Mendoza et al. (2005) en la parte media de la Formación Olinalá, fue compilado y utilizado para complementar los componentes de edad. La posición de las muestras en las secciones se indica en la Figura 2, mientras que los análisis individuales de los granos de circón se presentan en el suplemento (Tabla DR-1).

Las muestras Nemo-2 y Nemo-4 fueron colectadas respectivamente a $12 \mathrm{~m}$ y $48 \mathrm{~m}$ por arriba del contacto inferior de la Formación Olinalá (Figura 2). La separación de circones se realizó de acuerdo con las técnicas estandarizadas descritas en la literatura (e.g., Fedo et al., 2003; Pullen et al., 2011), mientras que para la preparación de muestras se siguió el procedimiento descrito por Solari et al. (2010). Con el objetivo de conocer la textura interna de los circones analizados y determinar los mejores sitios para la ablación laser se elaboraron imágenes de catodoluminiscencia. Las muestras fueron analizadas por ablación láser asociada a un espectrómetro de masas de plasma inductivamente acoplado (LA-ICP-MS del inglés: laser ablation-inductively coupled plasma-mass spectrometry) en el Laboratorio de Estudios Isotópicos (LEI, Centro de Geociencias de la Universidad Nacional Autónoma de México, UNAM). Para cada muestra se analizaron 100 granos que fueron elegidos al azar para obtener conjuntos de datos que permitieran reconocer componentes de edad (Vermeesch, 2004). Con el objetivo de eliminar edades con errores analíticos que pudieran llevar a inferencias erróneas, los análisis $\mathrm{U}-\mathrm{Pb}$ con una discordancia mayor a $20 \%$ o con una discordancia inversa $>5 \%$ fueron eliminados de los análisis y de las interpretaciones (Tabla DR-1). Los análisis concordantes fueron graficados con Isoplot (Ludwig, 2008). Este trabajo usa el marco cronoestratigráfico actualizado de Cohen et al. (2013).

\section{FACIES DE LA FORMACIÓN OLINALÁ}

Las facies terrígenas y carbonatadas de la Formación Olinalá reconocidas en este trabajo se describen a continuación. Las facies terrígenas incluyen: (1) arenisca conglomerática, (2) lutita negra laminada, (3) conglomerado polimíctico con estratificación cruzada, (4) arenisca con estratificación cruzada festonada, (5) conglomerado y arenisca de cuarzo y crinoides, (6) cuarzoarenita gradada y (7) arenisca bioturbada. Asimismo, se identificaron cinco facies carbonatadas que son: (8) wackestone de radiolarios, (9) packstone/grainstone de crinoides, briozoarios y braquiópodos, (10) biohermas de algas rojas coralináceas, (11) wackestone de fusulínidos y (12) packstone de braquiópodos arcilloso. Las facies terrígenas corresponden a depósitos marinos y continentales y las facies carbonatadas a depósitos marinos someros. La descripción e interpretación sobre el ambiente de depósito de las facies reconocidas en la Formación Olinalá se resumen en las Tablas 1 y 2.

\section{Facies Terrígenas}

\section{Facies 1: Arenisca conglomerática}

Descripción y distribución. Esta facies está constituida por arenisca rojiza de grano fino a mediano, la cual se presenta en la base de la sección Olinalá y, de manera discreta, en la parte inferior de la sección Nemotitlán. Cubre discordantemente a rocas metamórficas del Complejo Acatlán; esta no conformidad está afectada de manera local por una falla lateral. La facies 1 subyace concordantemente en ambas secciones a la facies de lutitas negras (descrita más adelante). En la parte inferior de la sección Olinalá, las capas de arenisca tienen una geometría tabular con bases erosivas que se extienden lateralmente varios metros. Cada estrato tiene un espesor que varía de 1-2 m, y presenta estratificación cruzada planar tenue. Las capas de arenisca inferiores comúnmente tienen lentes de guijas que miden 1-1.5 m de longitud y $15 \mathrm{~cm}$ de espesor; estos lentes son raros en las capas de arenisca hacia la cima de la sección (Figuras 3a y 3b). Las características de estos depósitos son similares a las descritas para las facies Sp de Miall (2006). Capas delgadas de arenisca de esta facies están localmente intercaladas con estratos de conglomerado de la facies 3 (descrita más adelante). Las muestras de arenisca de esta facies varían de arcosa madura a litarenita feldespática submadura moderadamente clasificada y cementada por hematita. Su armazón está constituido por granos subangulosos a subredondeados de cuarzo mono- y policristalino, microclina, ortoclasa y plagioclasa; en menor cantidad contiene fragmentos líticos (e.g., filita, gneis y esquisto) (Figura 3c). Los minerales accesorios son moscovita, biotita y circón.

Ambiente de depósito. Los rasgos sedimentológicos de estos depósitos permiten inferir un origen fluvial para esta facies, particularmente, representan dunas 2-D comunes en depósitos de planicie de 


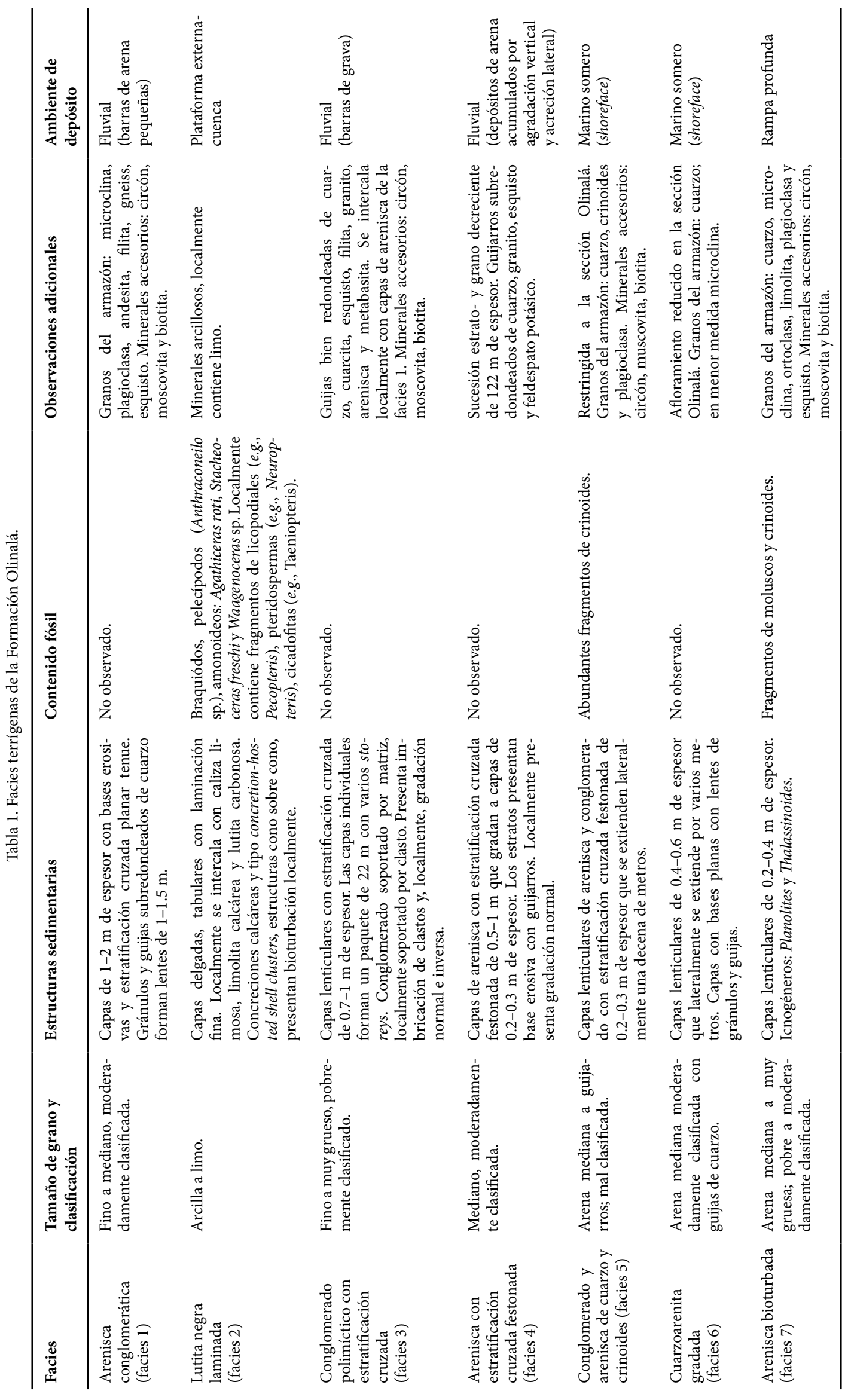


Tabla2. Facies carbonatadas de la Formación Olinalá.

\begin{tabular}{|c|c|c|c|c|c|}
\hline Facies & Textura & $\begin{array}{l}\text { Estructuras } \\
\text { sedimentarias }\end{array}$ & Contenido fósil & $\begin{array}{l}\text { Observaciones } \\
\text { adicionales }\end{array}$ & $\begin{array}{l}\text { Ambiente de } \\
\text { depósito }\end{array}$ \\
\hline $\begin{array}{l}\text { Wackestone de } \\
\text { radiolarios (facies 8) }\end{array}$ & $\begin{array}{l}\text { Wackestone- } \\
\text { mudstone }\end{array}$ & $\begin{array}{l}\text { Capas lenticulares } \\
\text { de } 0.2 \mathrm{~m} \text { de espesor } \\
\text { con laminación fina; } \\
\text { localmente bioturbadas. }\end{array}$ & Radiolarios y calciesferúlidos. & Conchas piritizadas. & $\begin{array}{l}\text { Rampa externa- } \\
\text { cuenca }\end{array}$ \\
\hline $\begin{array}{l}\text { Grainstone de } \\
\text { crinoides, briozoarios } \\
\text { y braquiópodos } \\
\text { (facies 9) }\end{array}$ & Grainstone- & $\begin{array}{l}\text { Capas de } 0.3-1.5 \mathrm{~m} \text { de } \\
\text { espesor con estratificación } \\
\text { cruzada, localmente } \\
\text { bioturbadas. }\end{array}$ & $\begin{array}{l}\text { Crinoides, braquiópodos, briozoarios (e.g., } \\
\text { Fistulipora, Megacanthopora), Tubiphytes, } \\
\text { pelecípodos, microforaminíferos, trilobites, } \\
\text { esponjas. }\end{array}$ & $\begin{array}{l}\text { Granos bien } \\
\text { redondeados de cuarzo } \\
\text { del tamaño de la arena. }\end{array}$ & $\begin{array}{c}\text { Bancos de arena } \\
\text { carbonatada }\end{array}$ \\
\hline $\begin{array}{l}\text { Bioherma de algas } \\
\text { rojas coralináceas } \\
\text { (facies } 10 \text { ) }\end{array}$ & Boundstone & $\begin{array}{l}\text { Estructuras in situ } \\
\text { en forma de domo } \\
\text { compuestas por } \\
\text { Archaeolithophyllum, } \\
\text { comúnmente bioturbadas. }\end{array}$ & $\begin{array}{l}\text { Crinoides, braquiópodos, moluscos } \\
\text { y briozoarios (e.g., Fistulipora, } \\
\text { Megacanthopora). }\end{array}$ & $\begin{array}{l}\text { Granos } \\
\text { subredondeados de } \\
\text { cuarzo del tamaño de } \\
\text { la arena. }\end{array}$ & $\begin{array}{c}\text { Bancos de arena } \\
\text { carbonatada }\end{array}$ \\
\hline $\begin{array}{l}\text { Wackestone } \\
\text { de fusulínidos (facies } \\
11)\end{array}$ & $\begin{array}{l}\text { Wackestone- } \\
\text { packstone }\end{array}$ & $\begin{array}{l}\text { Capas lenticulares de } 0.15 \\
\text { m de espesor. }\end{array}$ & $\begin{array}{l}\text { Fusulínidos (e.g., Parafusulina y } \\
\text { Polydiexodina), crinoides, briozoarios, } \\
\text { moluscos, braquiópodos, Tubiphytes. }\end{array}$ & $\begin{array}{l}\text { Granos de cuarzo del } \\
\text { tamaño del limo. }\end{array}$ & Rampa profunda \\
\hline $\begin{array}{l}\text { Packstone de } \\
\text { braquiópodos } \\
\text { arcilloso (F12) }\end{array}$ & $\begin{array}{l}\text { Packstone- } \\
\text { wackestone }\end{array}$ & $\begin{array}{l}\text { Capas tabulares de } \\
0.25-0.4 \mathrm{~m} \text { de espesor; } \\
\text { localmente laminadas. }\end{array}$ & $\begin{array}{l}\text { Braquiópodos (e.g., Waagenoconcha), } \\
\text { trilobites, crinoides, briozoarios (e.g., } \\
\text { Fistulipora), gasterópodos. }\end{array}$ & $\begin{array}{l}\text { Granos de cuarzo del } \\
\text { tamaño del limo. }\end{array}$ & Rampa profunda \\
\hline
\end{tabular}

inundación o pequeñas barras de arena (e.g., Miall, 2006). La geometría tabular de estas capas de arenisca y su extensión por varios metros apoyan esta interpretación. Facies similares han sido documentadas en depósitos fluviales pérmicos por Ghazi y Mountney (2009) en Salt Range, Pakistan.

\section{Facies 2: Lutita negra laminada}

Descripción y distribución. Está constituida por capas delgadas finamente laminadas de lutita negra y es la facies más abundante en la Formación Olinalá (Figuras $3 \mathrm{~d}-3 \mathrm{e}$ y $4 \mathrm{a}$ ). La facies 2 se presenta tanto en la parte inferior como en la parte superior de esta sucesión sedimentaria. Esta facies sobreyace abruptamente a la facies 1, y se intercala localmente con capas de wackestone de radiolarios de la facies 8 y con capas de arenisca de la facies 7 (ambas descritas más adelante). La facies de lutita negra laminada es sobreyacida discordantemente por estratos de conglomerado de la facies 3 (Figura 4b). Localmente la facies 2 se intercala con capas delgadas y poco extendidas de caliza limosa, limolita calcárea y lutita carbonosa (Figura 4a). En la parte inferior de la formación, esta facies está bioturbada, contiene abundantes micas y fragmentos de licopodiales (e.g., Pecopteris), pteridospermas (e.g., Neuropteris), cicadofitas (e.g., Taeniopteris), equisetales y coníferas (Silva-Pineda, 1991; Silva-Pineda et al., 1998; 2000). Sección arriba se distinguen al menos tres horizontes bien definidos de concreciones calcáreas cuyo diámetro varía de $20-40 \mathrm{~cm}$ (Figura 3d). Las concreciones de tipo concretion-hosted shell clusters, tienen un diámetro de $6-8 \mathrm{~cm}$ y localmente contienen fósiles bien preservados de braquiópodos, trilobites, amonoideos y pelecípodos marinos del género Anthraconeilo. En esta parte también se han reportado los amonoideos distintivos del Wordiano como Agathiceras rotii, Stacheoceras freschi y Waagenoceras (Vachard et al., 1993). En la parte media de la sucesión existen lentes delgados y discontinuos de limolita calcárea y de caliza limosa con estructuras de tipo cono sobre cono (Boggs, 1995; Lugli et al., 2005). En la cima de la formación, la coloración de esta facies es ligeramente rojiza y un horizonte de concreciones de algunos centímetros de espesor se extiende de forma continua por varios cientos de metros. Este elemento estratigráfico está constituido exclusivamente por concreciones limosas de $\sim 5-8 \mathrm{~cm}$ de diámetro con amonoideos. Todas estas características se presentan típicamente en facies de rampa profunda en el modelo de rampa homoclinal de Read (1985).

Ambiente de depósito. Las características sedimentológicas y paleontológicas de esta facies sugieren un depósito marino relativamente profundo para esta facies, por debajo del nivel base del oleaje normal, en un ambiente de plataforma externa-cuenca (offshore). La abundancia de micas en la parte inferior de esta facies sugiere la ausencia de corrientes y el predominio de aguas quietas al momento de su acumulación. Aunque se infieren condiciones de depósito relativamente homogéneas para esta facies, se registraron ligeras variaciones en las condiciones de depósito hacia la parte media de la unidad, donde la existencia local de lutitas negras carbonosas laminadas indica condiciones anóxicas predominantes (Burton y Link, 1991). En contraste, los niveles bioturbados sugieren condiciones mejor oxigenadas (Reading y Collinson, 1996). El origen marino profundo de esta facies es apoyado por la presencia de moluscos del género Anthraconeilo que ha sido documentada en facies de costafuera (e.g., Malinkey et al., 1986). Por otro lado, los depósitos de limolita calcárea con fragmentos de plantas hacia la parte media de la Formación Olinalá pudieron ser transportados hacia la cuenca por flujos de resaca después de eventos de tormenta. Esta interpretación es consistente con la existencia de concreciones tipo concretion-hosted shell clusters que son distintivas de este mismo tipo de condiciones (Tsujita, 1995). En este trabajo se interpreta que esta parte de la sucesión corresponde a depósitos de prodelta con base en las analogías que tiene con los ambientes sedimentarios actuales (Coleman y Prior, 1980; Coleman 1982; Reading y Collinson, 1996; Nichols, 2009). Sucesiones marinas similares han sido reportadas en la Formación Bearpaw en Alberta, Canadá (Tsujita, 1995), la Formación Ravnefjeld en Groelandia (Nielsen y Hanken, 2002), así como en la Lutita Bromley depositada en un sistema de rampa ordovícico en Kentucky-Ohio, Estados Unidos (McLaughlin et al., 2004).

\section{Facies 3: Conglomerado polimíctico con estratificación cruzada}

Descripción y distribución. En las secciones Olinalá y Nemotitlán, esta facies sobreyace discordantemente a la facies 2 a través de una 

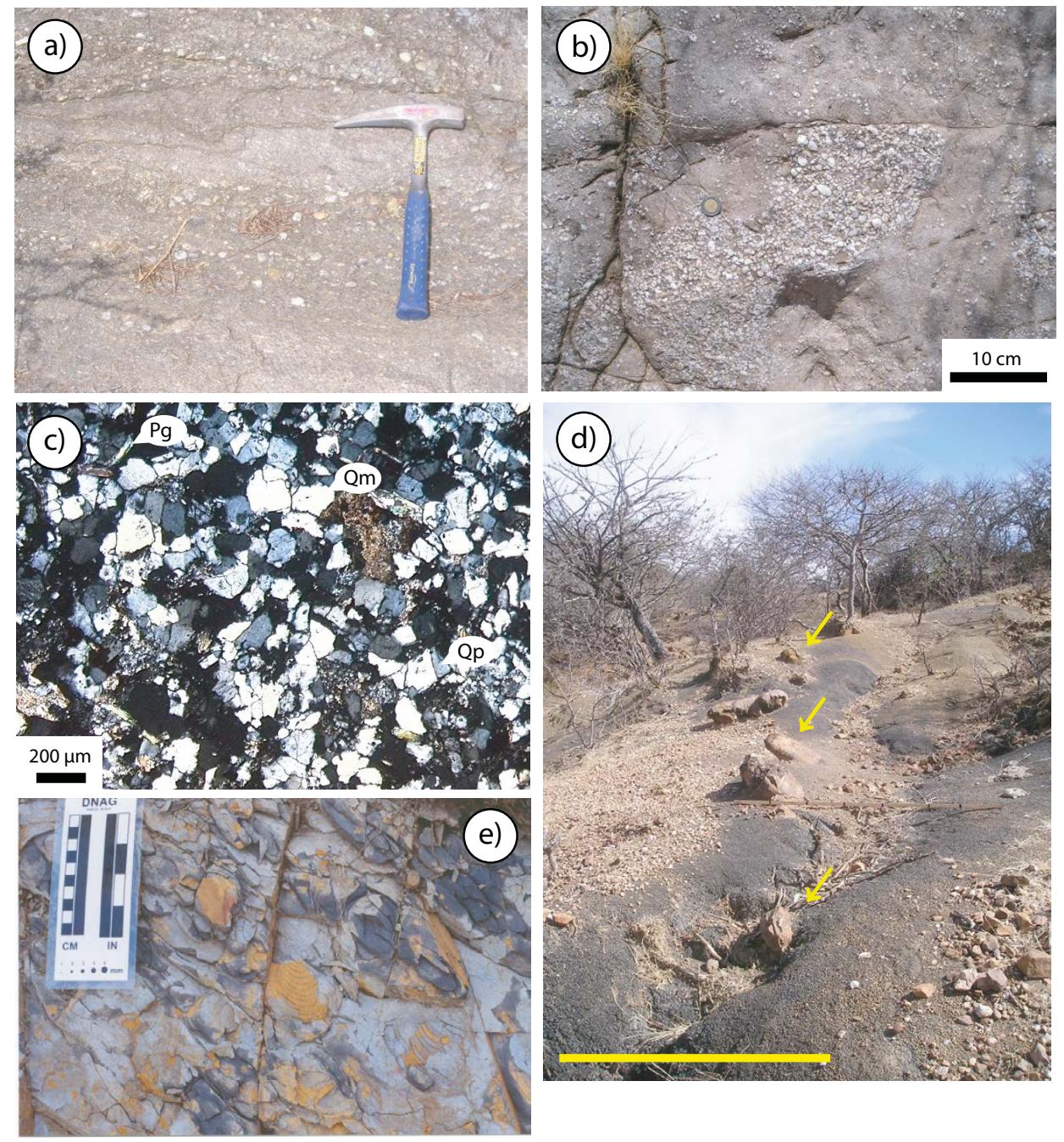

Figura 3. Arenisca conglomerática de la facies 1 y lutita negra de la facies 2. (a) Aspecto general de la facies 1 con lentes de guijas de cuarzo; el tamaño del martillo es $33 \mathrm{~cm}$. (b) Vista en planta de la facies 1. (c) Fotomicrografía con luz polarizada que muestra los principales componentes de las areniscas de esta facies. (d) Aspecto general de la facies 2 con horizontes de nódulos calcáreos (flechas en el centro de la imagen); el tamaño de la escala es $1.4 \mathrm{~m}$. (e) Impresiones de pelecípodos en la base de la Formación Olinalá; este conjunto fósil sugiere condiciones de salinidad normales durante su depósito; escala: $10 \mathrm{~cm}$. Abreviaturas: Qm, cuarzo monocristalino; Qp, cuarzo policristalino; Pg, plagioclasa.

superficie marcadamente erosiva. Su límite superior es concordante y subyace gradualmente a capas de arenisca con estratificación cruzada festonada de la facies 4 . La facies 3 está formada por capas rojizas de conglomerado pobremente clasificado con estratificación cruzada planar. En la sección Olinalá la capa de conglomerado inferior tiene aspecto masivo y su textura varía de soportada por clasto a soportada por matriz. En esta capa la mayoría de los ejes largos de los clastos están orientados paralelamente a la estratificación y es común la presencia de clastos imbricados. Sección arriba, cada capa individual tiene forma lenticular y un espesor que varía de 0.7-1 m; estas capas forman un paquete de $22 \mathrm{~m}$ con varios storeys que se cortan entre sí tanto lateral como verticalmente (Figura 4c). Localmente, los cuerpos lenticulares o en forma de cuña se intercalan con capas de arenisca de grano fino de la facies 1. Estas características son similares a las descritas para la facies Gp de Miall (2006). El grado de redondez de los clastos es variable, pero en su mayor parte se encuentran bien redondeados y su tamaño varía dentro del intervalo de $1-15 \mathrm{~cm}$, excepcionalmente ocurren guijarros de $>16 \mathrm{~cm}$ de diámetro. Los clastos están constituidos dominantemente por cuarzo, cuarcita, esquisto, filita, granito, arenisca y metabasita (Figura 4d). En la sección Nemotitlán esta facies es ampliamente dominada por guijas de cuarzo y granito subredondeadas a bien redondeadas. Localmente, esta facies cambia hacia la cima de ambas secciones medidas a capas de conglomerado con gradación normal e inversa, típica de la facies Gmg de Mial (2006). La arenisca que compone la matriz del conglomerado está dominada por cuarzo y fragmentos líticos, en menor proporción contiene microclina y plagioclasa sódica. Los minerales accesorios son moscovita, biotita y circón.

Ambiente de depósito. Los rasgos sedimentológicos y la arquitectura interna de esta facies son similares a los descritos para ambientes fluviales modernos (e.g., Allen, 1970; Collinson, 1996; Miall, 2006; Nichols, 2009). Particularmente, la amplia dominancia de capas lenticulares que se cortan una a otra, la pobre clasificación de clastos, las variaciones en la gradación y la característica estratificación cruzada planar de esta facies permiten inferir que estos depósitos constituyen barras de arena y bedforms (Gb) similares a las descritas por Miall (2006). Las direcciones de paleotransporte obtenidas de la imbricación de clastos en la base del conglomerado son limitadas e indican un transporte general hacia el sureste (Figura 5). Facies similares son 
descritas en una sucesión sedimentaria neoproterozoica en la cuenca de Taoudeni en el oeste de África (Benan y Deynoux, 1998) y en los depósitos fluviales del Pérmico en el área de Salt Range, Pakistán (Ghazi y Mountney, 2009).

\section{Facies 4: Arenisca con estratificación cruzada festonada}

Descripción y distribución. Esta facies está bien expuesta en la base de la sección Olinalá y de manera discreta en la parte inferior de la sección Nemotitlán. En ambas secciones sobreyace gradual y concordantemente al conglomerado de la facies 3 y subyace a través de una superficie abrupta a capas de lutita de la facies 2 . La facies 4 corresponde a una sucesión estrato- y grano- decreciente de $122 \mathrm{~m}$ de potencia, que incluye capas individuales de arenisca mediana de $0.5-1 \mathrm{~m}$ de espesor, las cuales gradan sección arriba a capas de arenisca de grano fino de $0.2-0.3 \mathrm{~m}$ de espesor. Los estratos presentan base erosiva con guijarros y se caracterizan por la presencia de estratificación cruzada festonada (Figura 4e); estos rasgos son típicos de la facies St de Miall (2006). Los clastos tienen el tamaño de los guijarros, son subredondeados y su composición es de cuarzo, granito, esquisto y feldespato potásico.

Ambiente de depósito. Los rasgos sedimentológicos de esta facies son similares a los descritos en ambientes fluviales modernos (e.g., Allen, 1970; Collinson, 1996; Miall, 2006). Basado en esta analogía, en la relación gradual y concordante que guarda con los depósitos de conglomerado de la facies 3 y su carácter estrato- y grano- decreciente se interpreta un origen fluvial para esta facies.

\section{Facies 5: Conglomerado y arenisca de cuarzo y crinoides}

Descripción y distribución. Esta facies sólo se documentó en la sección Olinalá, donde sobreyace de manera abrupta y erosiva a capas
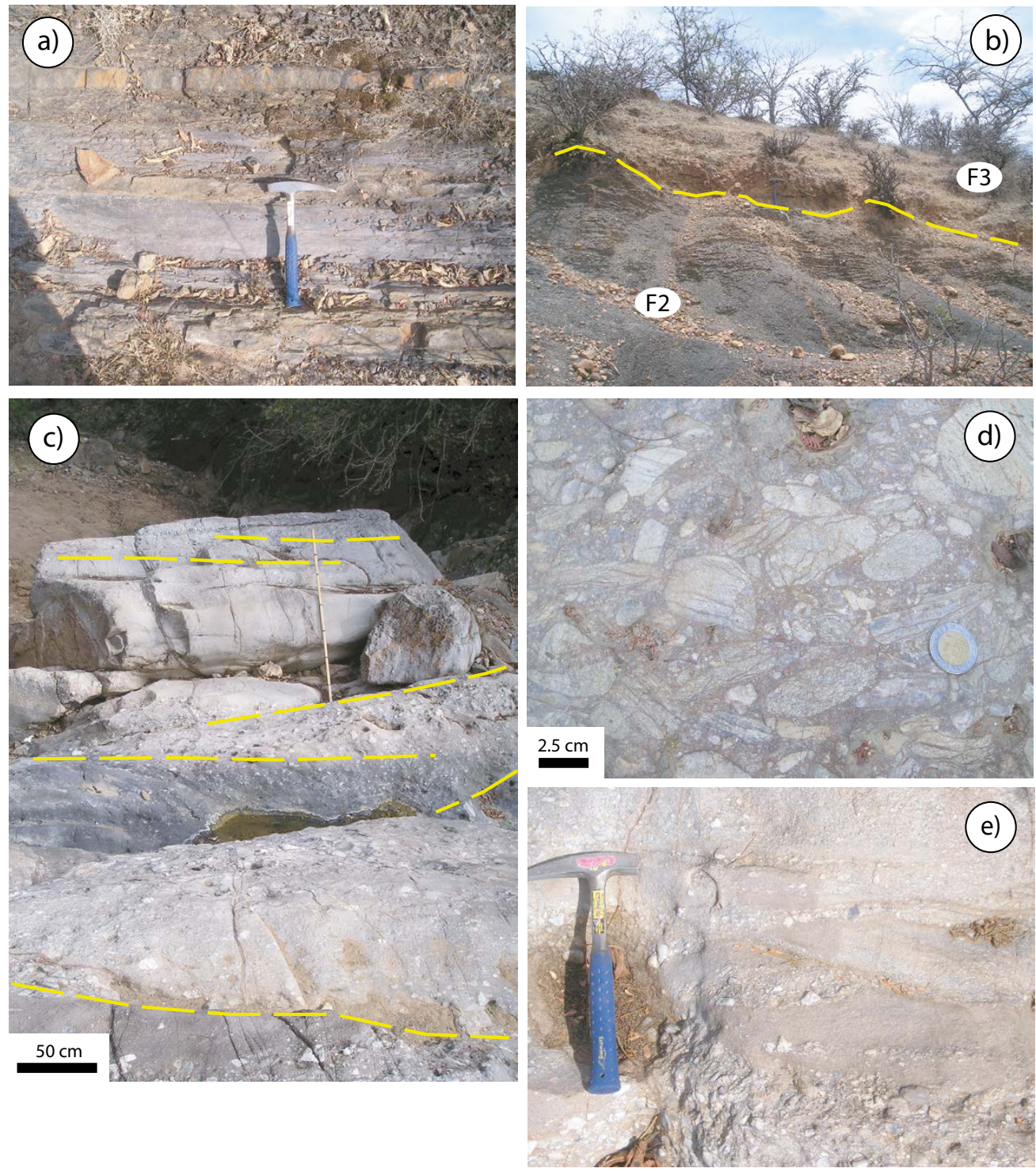

Figura 4. Lutita negra laminada de la facies 2 , conglomerado polimíctico con estratificación cruzada de la facies 3 y arenisca con estratificación cruzada festonada de la facies 4; el tamaño del martillo es $33 \mathrm{~cm}$. (a) Capas delgadas de limolita intercaladas localmente con capas de lutita. (b) Prominente discordancia que pone en contacto capas capas de lutita negra laminada de plataforma externa de la facies 2 (F2), con depósitos continentales fluviales de la facies 3 (F3). (c) En la imagen se resaltan en amarillo las superficies de estratificación en la facies 3. (d) Conglomerado soportado por matriz, mal clasificado, constituido dominantemente por clastos metamórficos bien redondeados de la facies 3. (e) Aspecto de la facies 4 con estratificación cruzada festonada característica. 
de lutita de la facies 2 y es cubierta por esta misma a través de una superficie erosiva. Esta facies está constituida por arenisca rojiza de grano mediano a grueso con estratificación cruzada festonada dispuesta en capas de $0.2-0.3 \mathrm{~m}$ de espesor, las cuales cambian gradualmente hacia la cima a conglomerado de grano fino con estratificación cruzada festonada (Figura 6a). Esta facies se distingue por la abundancia de guijas de cuarzo y de fragmentos de crinoides. La geometría de esta facies es lenticular y se extiende lateralmente de manera discontinua a través de una decena de metros. Los granos del armazón varían de subangulosos a subredondeados y son dominados por cuarzo y plagioclasa (Figura 6b). Los minerales accesorios incluyen muscovita, biotita y circón.

Ambiente de depósito. Los rasgos sedimentológicos de esta facies son similares a los descritos en ambientes de shoreface modernos (e.g., Nichols, 2009; Prothero y Schwab, 2014). En estos sitios, los depósitos son frecuentemente erosionados y su registro estratigráfico es incompleto (Prothero y Schwab, 2014). Ambas características se observan en campo para esta facies, por lo que basado en esta analogía se interpreta un ambiente marino somero.

\section{Facies 6: Cuarzoarenita gradada}

Descripción y distribución. Esta facies aflora de manera aislada y reducida en la sección Olinalá. La cuazoarenita está en contacto neto con capas de grainstone de crinoides, briozoarios y braquiópodos de la facies 9, mientras que su contacto superior también es neto con capas de packstone de braquiópodos arcilloso de la facies 12 (ambas facies son descritas más adelante). La facies 6 corresponde a una sucesión formada por capas individuales de arenisca fina a mediana y una geometría lenticular con un espesor entre 0.4-0.6 m, las cuales se extienden lateralmente por varios metros. Las capas tienen bases planas y comúnmente presentan lentes de gránulos y guijas de $10-15 \mathrm{~cm}$ de longitud. La arenisca de esta facies es una cuarzoarenita de grano mediano submadura, moderadamente clasificada, con guijas de cuarzo comunes (Figura 6c). La mayor parte de los granos del armazón son subredondeados y están dominados por cuarzo mono- y policristalino, en menor cantidad contiene microclina (Figura 6d).

Ambiente de depósito. Los rasgos sedimentológicos de esta facies son similares a los descritos en ambientes marinos someros modernos, particularmente en la zona de shoreface (e.g., Johnson y Baldwin, 1996; Nichols, 2009; Prothero y Schwab, 2014). En este sitio, las corrientes de marea fuertes forman cordones de arena de poco espesor, pero que se extienden lateralmente algunas decenas de metros (Johnson y Baldwin, 1996). Basado en esta analogía y en la relación que tiene con las facies carbonatadas de rampa media descritas más adelante, se infiere un ambiente de depósito marino somero.

\section{Facies 7: Arenisca bioturbada}

Descripción y distribución. Esta facies se presenta de manera discreta en la parte inferior de las secciones Olinalá y Nemotitlán, y comúnmente se intercala con la facies de lutita negra laminada. La facies 7 está formada por capas delgadas de arenisca gris de grano mediano que aumentan gradualmente su espesor hacia la parte alta de la sección. Geométricamente, esta facies está constituida por cuerpos tabulares que se extienden lateralmente por decenas metros hasta acuñarse. Localmente, los estratos presentan galerías cilíndricas subhorizontales de 10-15 mm de diámetro, las cuales se atribuyen a Thalassinoides (Figura 6e) o bien galerías cilíndricas, lisas, serpenteantes de espesor y configuración variables, similares al icnogénero Planolites. Estas areniscas corresponden a arcosas moderadamente clasificadas, con algunas capas delgadas ( $2 \mathrm{~cm}$ de espesor) de arenisca muy gruesa. Los granos del armazón varían de subangulosos a subredondeados, dominados por cuarzo mono- y policristalino, microclina, ortoclasa y

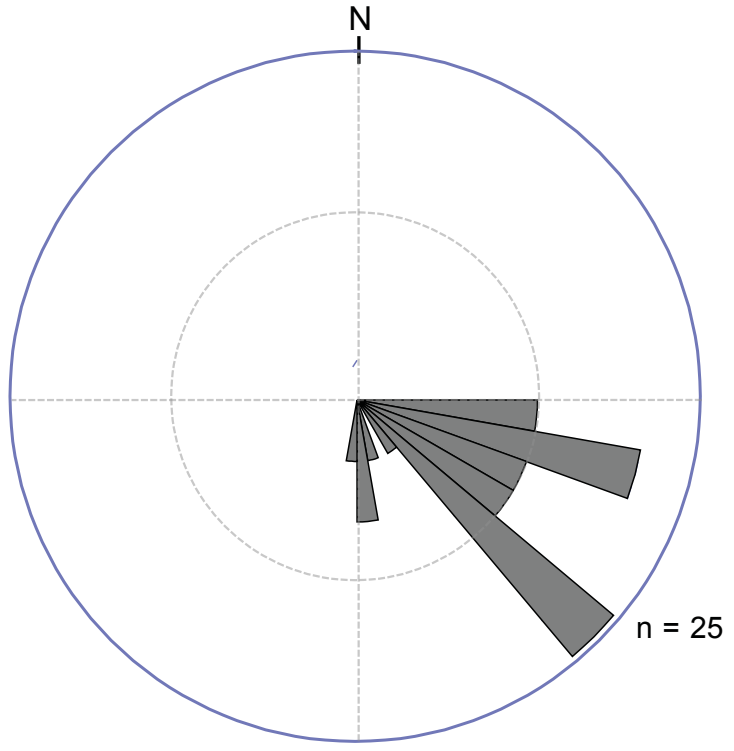

Figura 5. Diagrama de paleotransporte de clastos imbricados en la base del conglomerado de la facies 3 en la sección Olinalá. $n$ = número de mediciones.

plagioclasa sódica; en menor proporción contiene granos de esquisto, lutita, limolita, fragmentos de moluscos y placas de crinoides (Figura 6f). Los minerales accesorios incluyen muscovita, biotita (en algunos casos cloritizada) y circón.

Ambiente de depósito. Los icnofósiles, la presencia de fragmentos de moluscos y crinoides, así como la intercalación de esta facies con capas de lutita negra laminada sugieren que esta facies se depositó en condiciones marinas. Algunas características de esta facies como el acuñamiento de los estratos, el patrón estratocreciente observado en la base de la sección Olinalá (mismo que es evidencia de progradación) y la frecuente presencia de facies fluviales en la porción inferior de la Formación Olinalá, sugieren que estas areniscas pueden corresponder a depósitos de frente deltaico que fueron afectados por bioturbación y retrabajados por oleaje y marea (Coleman y Prior, 1980; Coleman 1982; Reading y Collinson, 1996; Olariu y Bhattacharya, 2006; Nichols, 2009). El icnogénero Thalassinoides es producto de la actividad de anomuros (e.g., camarones y cangrejos), los cuales son capaces de soportar constantes cambios en el ambiente y colonizar fondos suaves desde sistemas deltaícos hasta el shoreface (Pemberton et al., 2001). Su registro está bien documentado e incluye ambientes modernos como el delta Fraser en Columbia Británica (Swinbanks y Luternauer, 1987), el sistema deltaico turoniano Notom, del Miembro Arenisca Ferron del sur de Utah (Li et al., 2011), así como sistemas marinos pérmicos como los preservados en la Formación Rio Bonito de la cuenca de Paraná (Buatois et al., 2001) y la Formación Hueco de la cuenca Orogrande en el sur de Nuevo México (Mack et al., 2003).

\section{Facies Carbonatadas}

\section{Facies 8: Wackestone de radiolarios}

Descripción y distribución. Esta facies se presenta en la base de las secciones Olinalá y Nemotitlán, donde se extiende lateralmente por varios metros y se intercala con la facies de lutita negra laminada. La facies 8 está formada por capas delgadas de caliza negra de $10-15 \mathrm{~cm}$ de espesor (Figura 7a), algunas de las cuales presentan bioturbación. Esta facies consiste en calizas finamente laminadas con alto contenido de materia orgánica oxidada, abundantes radiolarios y calciesferúlidos 


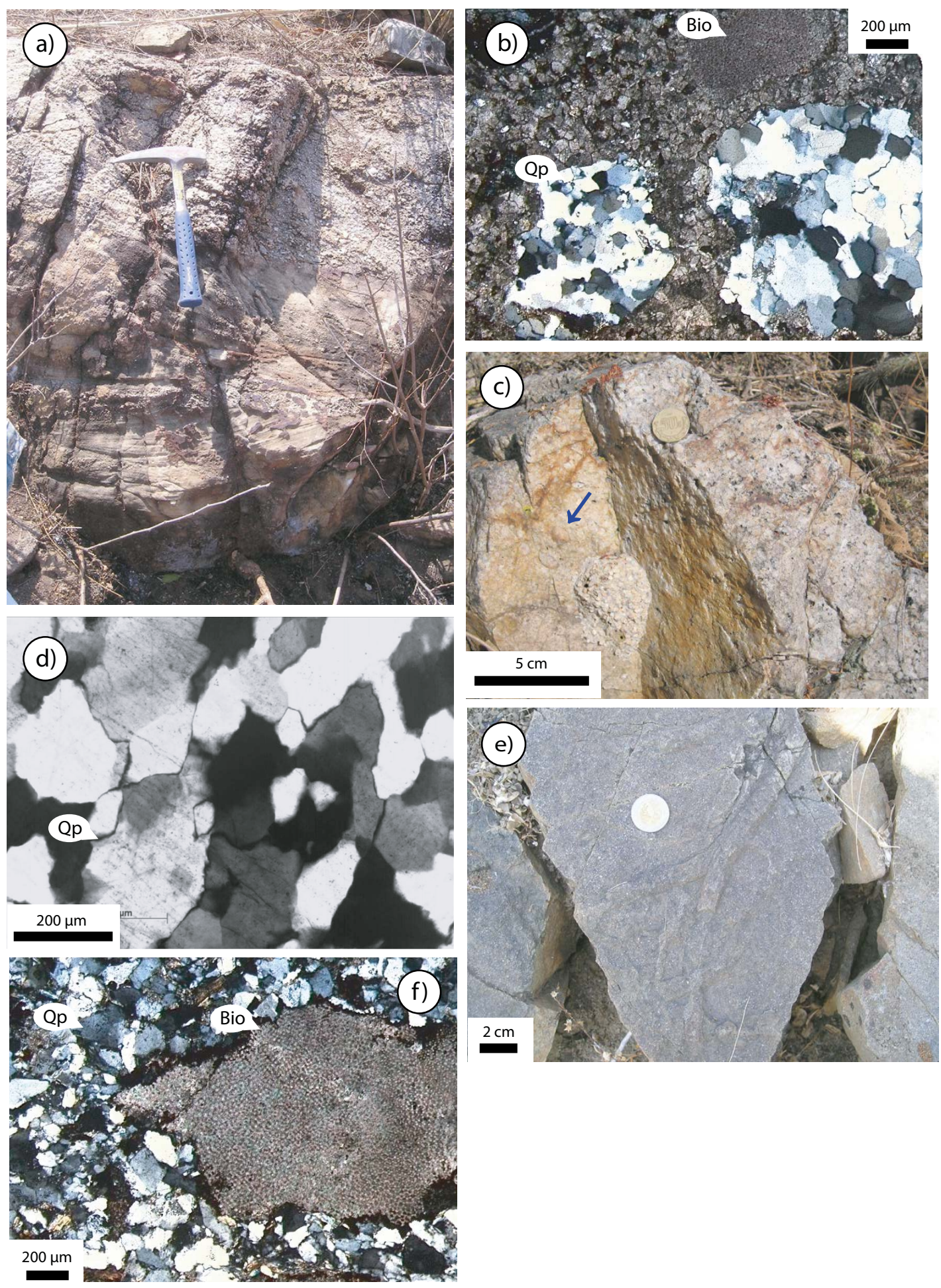

Figura 6. Conglomerado y arenisca de cuarzo y crinoides de la facies 5, cuarzoarenita gradada de la facies 6 y arenisca bioturbada de la facies 7. (a) Aspecto general de la facies 5 con estratificación cruzada planar de bajo ángulo, compuesta dominantemente por guijarros de cuarzo subredondeados y fragmentos de crinoides; el tamaño del martillo es de $33 \mathrm{~cm}$. (b) Principales componentes del armazón de esta facies. (c) Arenisca mal clasificada con abundantes guijas de cuarzo redondeadas (flecha) de la facies 6. (d) Principales componentes del armazón en las areniscas de esta facies. (e) Aspecto de la facies 7 con numerosas galerías de Thalassinoides. (f) Componentes del armazón de esta facies. Todas las fotomicrografías fueron tomadas con luz polarizada. Abreviaturas: Qp, cuarzo policristalino; Bio, bioclasto (placas de crinoides). 
que comúnmente están piritizados (Figura $7 \mathrm{~b}$ ). Las características mencionadas son típicas de facies de rampa profunda en el modelo de rampa homoclinal de Read (1985).

Ambiente de depósito. La combinación de estructuras sedimentarias, alto contenido de materia orgánica, así como la abundancia de radiolarios y calciesferúlidos permiten inferir que esta facies corresponde a una sección condensada depositada en condiciones relativamente profundas y de baja energía dentro de la platafotma externa-cuenca. La presencia de bioclástos piritizados sustenta esta interpretación y sugiere además condiciones euxínicas, como ha sido documentado en otras sucesiones paleozoicas (e.g., Nielsen y Hanken, 2002; McLaughlin et al., 2004). Este tipo de depósitos ocurren comúnmente dentro de la zona de costafuera (Loutit et al., 1988).

\section{Facies 9: Grainstone de crinoides, briozoarios y braquiópodos}

Descripción y distribución. Es la facies composicional y texturalmente más diversa en la Formación Olinalá, se presenta en estratos del- gados y gruesos de caliza gris con estratificación cruzada; los contactos entre las capas son moderadamente ondulosas (Figura 7c). Esta facies está presente en todas las secciones estratigráficas estudiadas infrayace y sobreyace a la facies 2 . La facies 9 está constituida dominantemente por bioclastos de crinoides, briozoarios (e.g., Megacanthopora, Fistulipora y Meekanthopora) y braquiópodos bien redondeados y clasificados (Figuras 7d-7e). En menor medida contiene fragmentos de esponjas calcáreas, gasterópodos, pelecípodos, microforaminíferos, ostrácodos, Tubiphytes, trilobites y calcimicrobios semejantes a Girvanella y Epiphyton. Los fragmentos de Tubiphytes están asociados a briozoarios, estructuras geopetales y pellets. En la sección Xochimilco esta facies está afectada por diversos grados de dolomitización que modifican su textura original. Las características descritas son típicas de las facies de bancos de arena en el modelo de rampa homoclinal de Read (1985).

Ambiente de depósito. Facies similares han sido documentadas en la cuenca pérmica de Sverdrup (Morin et al., 1994), quienes atribuyen la gran diversidad de bioclastos a distintos niveles de restricción en
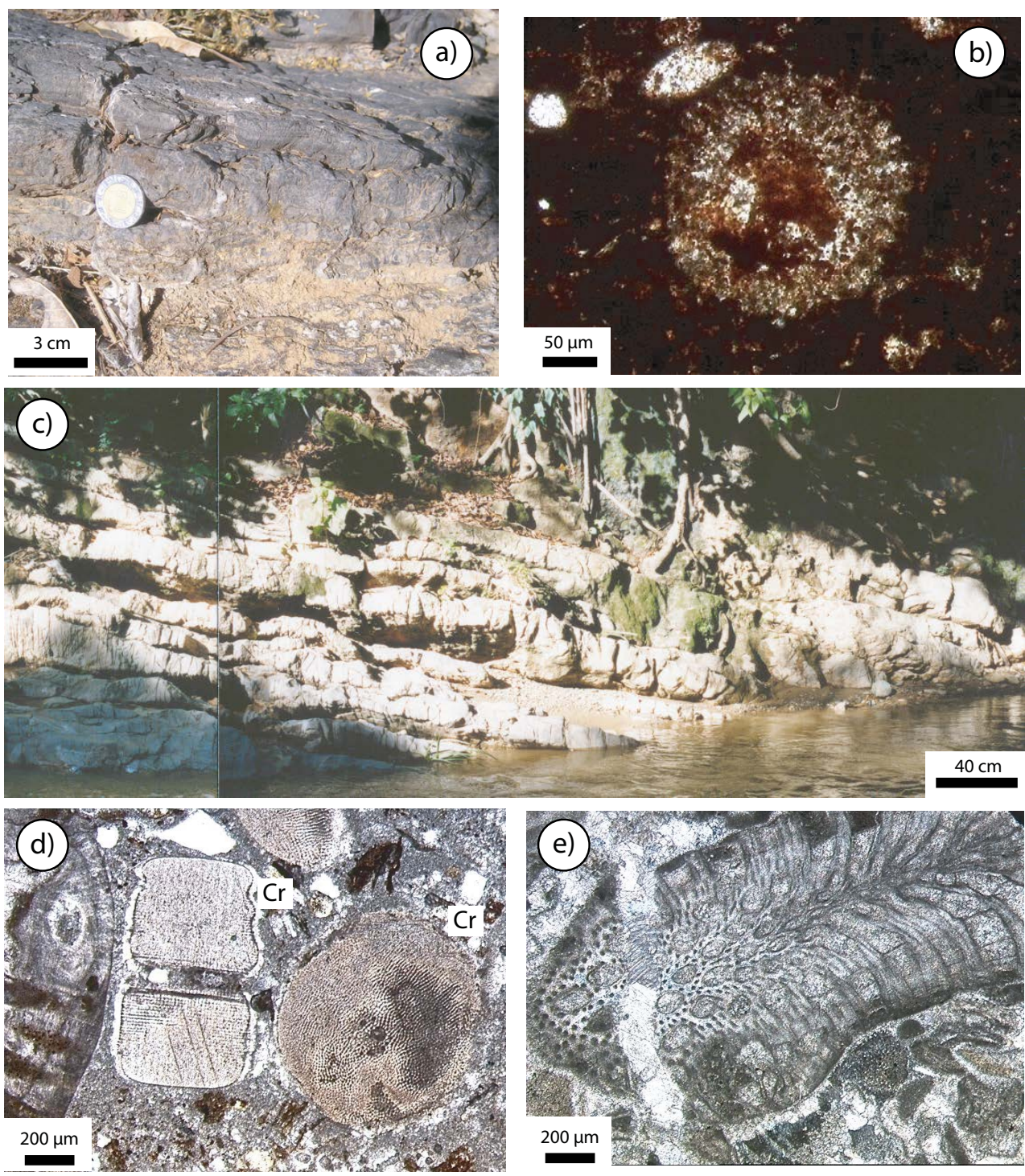

Figura 7. Facies de wackestone de radiolarios de la facies 8 y grainstone de crinoides, briozoarios y braquiópodos de la facies 9. (a) Aspecto general de la facies 8 cerca de la base de la Formación Olinalá. (b) Detalle de radiolario característico en esta facies. (c) Calizas en la sección Xochimilco dispuestas en capas delgadas y medianas de la facies 9. (d) Packstone dominado por crinoides y braquiópodos. (e) Grainstone, fragmento de briozoario en la imagen. Todas las fotomicrografías fueron tomadas con luz polarizada. Abreviatura: $\mathrm{Cr}$, crinoide. 
la circulación marina. De acuerdo con la variación de las texturas depositacionales en esta facies, las condiciones hidrodinámicas durante el depósito fueron variables, predominando alta energía. Esta idea es apoyada por la presencia de bioclastos con huellas de abrasión y una discreta orientación de granos, así como abundantes organismos incrustantes (e.g., Fistulipora y Meekanthopora). La abundancia de Tubiphytes en esta facies sugiere la existencia de biohermas formados dentro de la rampa interna (Morin et al., 1994). Por otro lado, la abundancia de crinoides, moluscos, braquiópodos y microforaminíferos indica condiciones marinas normales y aguas cálidas, propias de ambientes tropicales o subtropicales (Ross y Ross, 1988; McLaughlin et al., 2004). Esta facies se interpreta como bancos de arenas carbonatadas acumuladas en la rampa interna, con base en su geometría, estructuras sedimentarias primarias y relaciones de contacto entre los estratos, así como en la abrasión de los elementos esqueletales, la ausencia de lodo carbonatado y la abundancia de organismos incrustantes.

\section{Facies 10: Bioherma de algas rojas coralináceas}

Descripción y distribución. En su parte superior, la Formación Olinalá contiene esporádicamente pequeñas construcciones carbonatadas de origen orgánico, las cuales tienen formas tabulares y dómicas de 8-20 cm de longitud. Estas estructuras están formadas por láminas de aspecto contorsionado y se presentan en la base de los estratos preservando su posición de crecimiento, por lo que se interpretan como depósitos in situ (Figura 8a). La parte media de la sección Nemotitlán presenta la mejor exposición de esta facies donde se encuentra intercalada con capas de grainstone de crinoides, briozoarios y braquiópodos (facies 9). Las estructuras dómicas son formadas por algas rojas coralináceas atribuidas a Archaeolithophyllum. Esta facies contiene además abundantes esponjas calcáreas y briozoarios incrustantes (e.g., Fistulipora y Meekanthopora) (Figura 8b) que en su conjunto formaron pequeños montículos arrecifales (reef mounds). Menos comunes son los fragmentos de crinoides, braquiópodos y agregados de peloides.

Ambiente de depósito. Actualmente, las algas rojas coralinas son organismos incrustantes que crecen en forma de placas muy irregulares que prosperan en profundidades de hasta $100 \mathrm{~m}$ (Adey y Macintyre, 1973; Testa y Bosence, 1999). Los peloides, esponjas calcáreas, briozoarios, crinoides y braquiópodos son componentes comunes en comunidades arrecifales pérmicas (Flügel, 2004). Además, su carácter de depósitos in situ, su continuidad lateral y su asociación con la facies 9 sugieren condiciones de fuerte oleaje. Facies similares se han documentado en la Formación Auernig del Pensilvánico en los Alpes cárnicos (Krainer, 2007), en la Caliza Hueco de la cuenca de Orogrande, Nuevo México (Scholle y Scholle, 2003) y en la Caliza Midale Vuggy de la Formación Charles de la cuenca Willistone, en el centro de Canadá (Shen y Qing, 2008).

\section{Facies 11: Wackestone de fusulínidos}

Descripción y distribución. Esta facies tiene una textura de wackestone/packstone; se presenta en la parte media de la sección Nemotitlán y se intercala con la facies 9 . Se presenta en estratos delgados y lenticulares de caliza gris, caracterizados por la abundancia de fusulínidos de los géneros Parafusulina y Polydiexodina (Figuras 8c y 8d) (Vachard et al., 1993). En menor cantidad contiene fragmentos de crinoides, briozoarios, moluscos, equinodermos, ostrácodos y Tubiphytes.

Ambiente de depósito. Esta facies fue depositada en condiciones de baja energía donde dominó la acumulación de lodo carbonatado. La geometría de los estratos, relaciones estratigráficas, composición y contenido fósil, así como las restricciones ambientales de los fusulínidos, sugieren un depósito bajo condiciones marinas normales tropicales y profundidades de $\sim 50$ m (Ross y Ross, 1988; Morin et al., 1994). Es posible que estos depósitos se hayan formado durante un periodo de nivel del mar alto, cuando la plataforma se encontraba inundada, como se ha interpretado en la cuenca pérmica de Sverdrup, en el ártico de Canadá (McLaughlin et al., 2004).

\section{Facies 12: Packstone de braquiópodos arcilloso}

Descripción y distribución. La facies 12 aflora en la parte media de la Formación Olinalá y su mejor exposición se presenta en la sección homónima, mientras que en la sección Nemotitlán su textura varía a wackestone. Esta facies sobreyace concordantemente a la facies 6 (cuarzoarenita gradada) y cambia de manera transicional a la facies 9 (grainstone de crinoides, briozaorios y braquiópodos). La facies $12 \mathrm{se}$ presenta en estratos delgados a medianos de caliza limosa, con contactos entre capas ligeramente irregulares. Se distingue por su contenido fósil, el cual está dominado por braquiópodos bien conservados pertenecientes a las familias Echinoconchidae, Productidae, Athyrididae y Dielasmatidae (Figuras 8e y 8f). Todos estos grupos y en particular el género Waagenoconcha son abundantes en rocas carbonatadas de plataforma del Paleozoico medio y superior (Ross y Ross, 1988). Esta facies incluye también pelecípodos, gasterópodos, corales solitarios, crinoides, briozoarios y microforaminíferos.

Ambiente de depósito. Las relaciones estratigráficas de esta facies, abundancia y diversidad de braquiópodos y de otros bioclastos sugieren un ambiente marino con condiciones de salinidad normales. Por otro lado, el depósito abundante de detritos clásticos finos y la existencia de estratificación delgada permiten inferir condiciones de moderada energía, posiblemente debajo el nivel base del oleaje normal.

\section{Asociación de facies y ambientes de depósito de la Formación Olinalá}

Las facies antes descritas se agruparon en asociaciones verticales genéticamente relacionadas para reconocer los distintos ambientes de depósito registrados en las secciones medidas. De esta manera, la asociación de facies permitió dilucidar la evolución sedimentaria de este sistema pérmico a través del tiempo.

\section{Asociación de facies continentales fluviales}

Está constituida por depósitos de conglomerado y arenisca fluviales (facies 1, 3 y 4), los cuales comúnmente cambian de manera transicional entre sí, o están localmente intercalados. Los mejores afloramientos se encuentran en la base de la sección Olinalá, en la cual esta asociación de facies sobreyace por contacto erosivo a la asociación de facies de rampa externa descrita más adelante. El conjunto de facies y la arquitectura interna de los depósitos de conglomerado son típicos de las barras de graba y bedforms (gravel bars and bedforms, GB) de Miall (2006). Localmente, pequeñas barras de arena de la facies 1 estarían asociadas a este elemento arquitectural. El potente depósito de arenisca de la facies 4 fue designado como DA/LA (downstream-accretion macroforms/ lateral-accretion deposits) de Miall (2006). Esta designación obedece a que ambos elementos están formados por facies similares y los datos de campo son limitados para discriminar la geometría de la acreción, misma que es determinante para separar estos elementos.

\section{Asociación de facies marinas de rampa homoclinal}

La distribución de facies marinas y su cambio transicional de aguas someras a profundas, así como la ausencia de barreras arrecifales, de depósitos de talud y turbiditas sugieren un ambiente de rampa con condiciones marinas someras que cambian transicionalmente a condiciones de cuenca. Con base en estas características interpretamos un sistema de depósito de rampa de tipo homoclinal (sensu Ahr, 1985; Read, 1985; Burchette y Wright, 1992). Las asociaciones de facies de rampa incluyen: 
Bancos de arena carbonatada (shoal-water complex sensu Read, 1985). Las facies 9 y 10 que componen esta asociación constituyen los depósitos carbonatados volumétricamente más importantes de la Formación Olinalá. Esta asociación de facies aflora excepcionalmente en la sección Nemotitlán, donde cambian lateralmente a facies de rampa profunda o subyacen a la asociación de facies de rampa externa. Los bancos de arena carbonatada muestran los rasgos típicos descritos por Read (1985), ya que están compuestos por una gran diversidad de bioclastos de origen marino, se extienden lateralmente varias decenas de metros y comúnmente están bioturbados. Estrechamente asociados a estos bancos se desarrollaron biohermas de algas rojas coralináceas en las zonas de mayor energía.

Rampa profunda (deeper ramp sensu Read, 1985). Esta asociación está formada por capas de arenisca bioturbada de la facies 7, y los depósitos carbonatados de las facies 11 y 12. Las facies de rampa profunda están bien expuestas en ambas secciones, aunque los mejores afloramientos están en la parte media de la sección Olinalá, en donde cambian lateralmente a la asociación de facies de bancos de arenas carbonatadas o son cubiertas por la asociación de facies de rampa externa, descrita más adelante. Esta asociación de facies está dominada por rocas con texturas ricas en lodo comúnmente bioturbadas (e.g., wackestone y packstone arcilloso) y, constituida por bioclastos marinos abundantes y diversos (e.g., moluscos, equinodermos, foraminíferos y braquiópodos).

Rampa externa (slope and basin sensu Read, 1985). Incluye los depósitos de rampa externa-cuenca; esta asociación está constituida por la facies de lutita negra laminada, que es la unidad dominante en la Formación Olinalá y, la facies de wackestone de radiolarios que representa una facies subordinada. Los depósitos de rampa externa cubren a la asociación de facies de rampa profunda y subyacen por
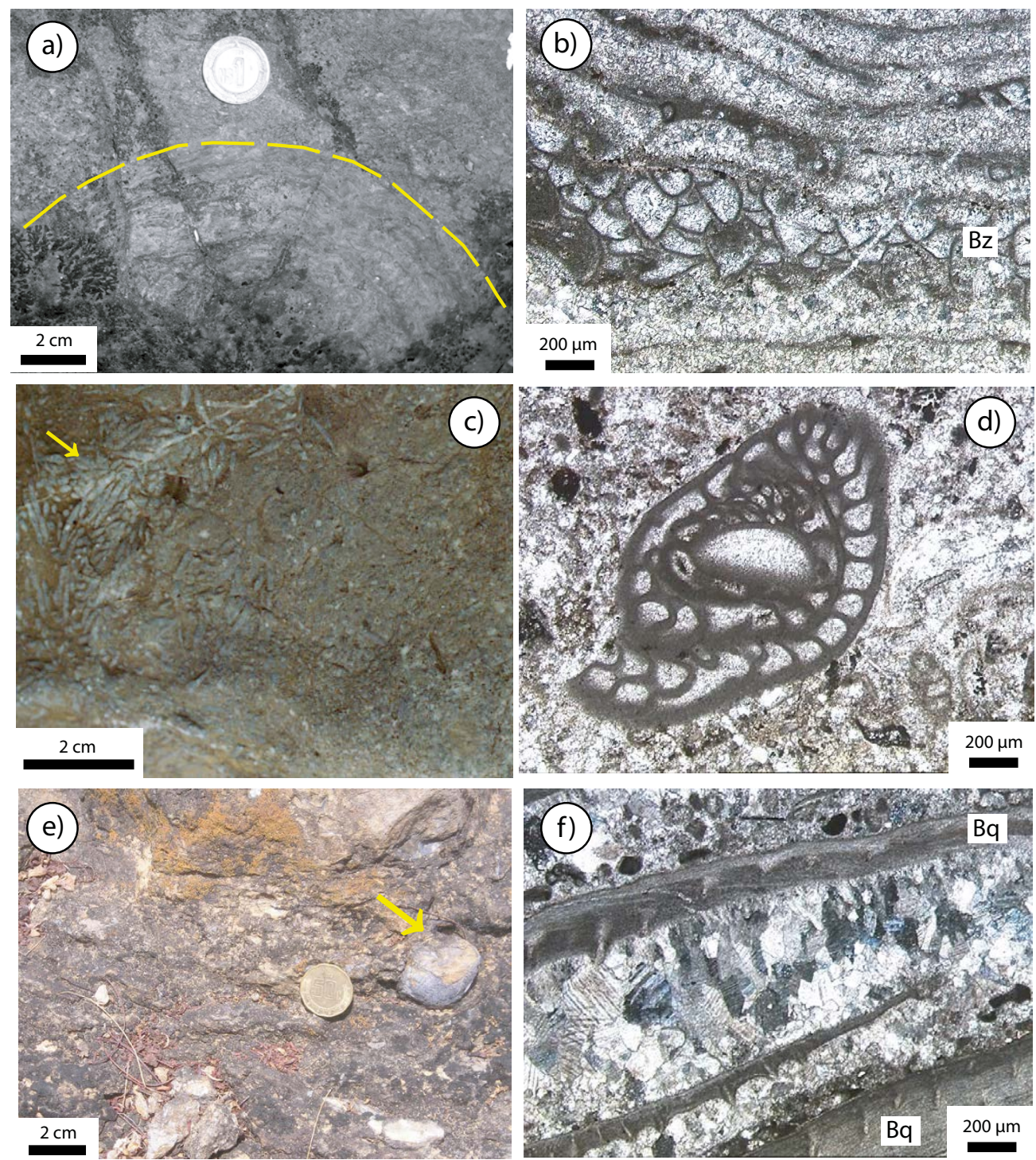

Figura 8. Facies de biohermas de algas rojas coralináceas de la facies 10, wackestone de fusulínidos de la facies 11 y packstone de braquiópodos arcilloso de la facies 12. (a) Aspecto general de la facies 10 con estructuras en forma de domo (indicadas en amarillo); note su posición in situ en la base del estrato. (b) Las estructuras están constituidas dominantemente por Archaeolithophylum (alga roja coralinácea) y briozoarios incrustantes. (c) Aspecto general de la facies 11 con abundantes fusulínidos (flecha). (d) Parafusulina sp., género que permite asignar una edad capitaneana a la parte media de la Formación Olinalá. (e) Caliza arcillosa dispuesta en capas delgadas de la facies 12 con abundantes braquiópodos del género Waagenoconcha (flecha). Todas las fotomicrografías fueron tomadas con nícoles cruzados. (f) Fragmentos de braquíopodos. Abreviaturas: Bq, braquiópodo; Bz, briozoario. 
contacto erosivo a la asociación de facies fluviales. Esta asociación está compuesta dominantemente por lutita dispuesta en capas delgadas, finalmente laminadas y lateralmente continuas por varias decenas o centenas de metros. Localmente, esta asociación incluye otros depósitos pelíticos (e.g., lutita carbonosa o limolita calcárea), y capas de lutita con abundantes concreciones y fósiles de mar abierto (e.g., amonoideos).

\section{Geocronología U-Pb en circones detríticos}

Los granos de circón analizados son dominantemente fragmentos subredondeados y en menor cantidad tienen formas euhedrales con caras abrasionadas. Los cristales son comúnmente alargados y la imagen de catodoluminiscencia permitió reconocer que cerca del $25 \%$ del total de los granos presenta textura oscilatoria, en el resto de los granos no se reconoció una textura específica. Las edades de circón detrítico de la base de la Formación Olinalá varían dentro de un amplio intervalo de edad que abarca $\sim 2262-256 \mathrm{Ma}$. Los granos del Pérmico son escasos y sólo 55 ( $22 \%$ ) de 253 análisis totales tienen una edad $<550 \mathrm{Ma}$ (Figura 9). Se reconocen cinco componentes de edad basados en el total de los análisis: (A) el grupo del Paleoproterozoico tardío ( 1.8-1.75 Ga) representa el $2 \%$ de la población; (B) el grupo del Mesoproterozoico medio-Neoproterozoico temprano ( 1554-732 Ma) representa el componente dominante con $70 \%$ de los granos analizados y contiene un subcomponente de edad bien definido correspondiente al Mesoproterozoico ( 1.3-0.9 Ga); (C) el grupo del Neoproterozoico tardío ( 668-551 Ma) constituye el $5 \%$ del total de los análisis; (D) el grupo del Paleozoico inferior ( 483-442 Ma) representa el $9 \%$ de los granos analizados, y (E) el componente de edad Pensilvánico-Pérmico ( 318-256 Ma), constituye el $11 \%$ del total (Figura 9).

\section{DISCUSIÓN}

\section{Modelo de depósito}

Flores de Dios et al. (2000) y Silva-Pineda et al. (2003) dedujeron inicialmente la presencia de depósitos de rampa en la Formación Olinalá a partir de estudios locales en esta unidad. Sin embargo, varios aspectos sobre el arreglo y significado de la gran diversidad de facies en esta formación no fueron esclarecidos. En este trabajo se propone un modelo de depósito para este sistema pérmico a partir de un detallado análisis de las asociaciones de facies reconocidas, el cual se describe a continuación.

Las secciones Olinalá y Nemotitlán permitieron reconocer los ambientes de depósito que se sucedieron en el tiempo. La base de la Formación Olinalá se caracteriza por los depósitos de conglomerado arreglados en el elemento arquitectural GB y el potente paquete de arenisca que constituye el elemento arquitectural DA/LA, definidos de acuerdo al esquema de Miall (2006). El elemento GB registra condiciones de depósito de alta energía como las presentes en sistemas fluviales de grano grueso durante la migración de canales. Su relación concordante y transicional con el elemento DA/LA representa la acumulación de sedimentos por dos procesos principales: agradación vertical y acreción lateral. Adicionalmente, el carácter estrato- y granodecreciente de esta asociación de facies es típico de un proceso de relleno de canal fluvial, el cual tiene un significado geológico importante si consideramos que las barras fluviales son una guía aproximada de la profundidad mínima del canal contenedor (Miall, 2006). A partir de esto, se interpreta que los depósitos fluviales en la base de la Formación Olinalá representan un ilustrativo ejemplo de un relleno de valle de incisión fluvial, cuya profundidad fue de al menos $130 \mathrm{~m}$. El reconocimiento de este elemento permite además deducir importantes variaciones en el nivel del mar (Le Cotonnec et al., 2020). De acuerdo con lo anterior inferimos que los depósitos marinos en la parte inferior de la Formación Olinalá fueron erosionados por sistemas fluviales regionales cuando el nivel del mar bajó y dejó expuesta parte de la plataforma (Figura 10a).

Durante este episodio de depósito, los sedimentos finos transportados por ríos fueron retrabajados por oleaje y mareas al llegar a la cuenca y fueron depositados cerca de la costa (shoreface). Un poco más profundo, capas de arena esporádicamente bioturbadas sugieren variaciones físico-químicas debido a la mezcla de aguas dulces y marinas, lo que generó un entorno desfavorable para el desarrollo de comunidades bentónicas marinas, aunque algunos organismos oportunistas como los anomuros fueron capaces de soportar constantes cambios en el ambiente y colonizar esta zona. Estas características pudieron existir durante el depósito de la facies 7 . Hacia la parte más profunda de la rampa se depositaron capas de lutita negra laminada (facies 2) y capas delgadas de caliza ricas en radiolarios (facies 8).

La parte media de la Formación Olinalá caracterizada por una potente y diversa asociación de facies carbonatadas ilustra la evolución

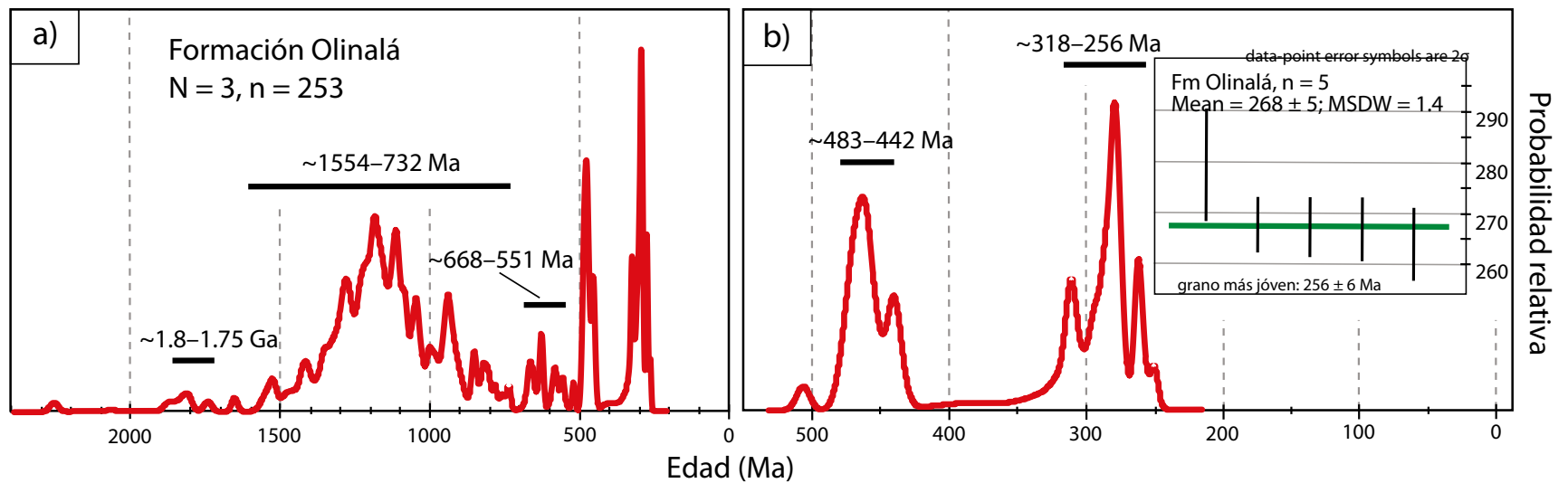

Figura 9. Curvas de densidad de probabilidad en las que se muestra la distribución de las edades U-Pb obtenidas en granos de circón detrítico de las muestras ACA-502 (Talavera-Mendoza et al., 2005), Nemo-2 y Nemo-4 de la Formación Olinalá. (a) Todos los granos analizados para la Formación Olinalá. (b) Distribución de edades de los granos fanerozoicos. En el recuadro, la edad máxima de depósito calculada a partir de los cinco granos más jóvenes de las tres muestras mencionadas que se superponen con un error de $2 \sigma$. Las barras horizontales y las etiquetas corresponden a los componentes de edad descritos en el texto. $\mathrm{N}=$ número de muestras, $\mathrm{n}=$ número de análisis. 
de una rampa carbonatada desarrollada en aguas cálidas bajo condiciones marinas normales. Esta parte de la formación registra depósitos que incluyen desde la rampa somera (por debajo del nivel de marea baja) hasta la rampa profunda (por debajo del nivel base del oleaje de tormenta). Las observaciones de campo sugieren que la distribución de los bancos de arena carbonatada formaron un tracto continuo a través de decenas de metros donde prevalecieron condiciones de alta energía debido a la acción del oleaje, pero no se reconocieron rasgos estratigráficos o petrográficos de facies de laguna (e.g., ciclos de submarea y supramarea).

Durante este episodio de depósito, el nivel del mar alto favoreció el establecimiento de una fábrica de carbonatos saludable con componentes diversos y abundantes. En la parte somera de la rampa se formaron bancos de arena carbonatada (facies 9), sobre las cuales se desarrollaron localmente pequeños biohermas de algas rojas coralináceas. Estos elementos fueron volumétricamente poco relevantes, pero formaron comunidades arrecifales diversas. Los pequeños biohermas estuvieron constituidos por Archaeolithophylum y en menor medida por esponjas calcáreas, briozoarios (e.g., Fistulipora y Meekanthopora), Tubiphytes y otros organismos incrustantes. Aunque las condiciones energéticas altas prevalecieron en este ambiente, la presencia local de packstone sugiere condiciones energéticas variables posiblemente como consecuencia de cambios en la circulación marina causada por la migración de la arena. Un poco más profundo sobre el perfil de la rampa $(\sim 50 \mathrm{~m})$, donde predominaron condiciones adecuadas de temperatura, nutrientes y oxigenación, se depositaron facies carbonatadas lodosas ricas en fusulínidos (facies 11). Condiciones ambientales similares, pero con fondos arenosos, habrían sido favorables para el establecimiento de comunidades de braquiópodos prodúctidos que usaban sus espinas para anclarse al fondo. Asociados a estos organismos se encontraban gasterópodos, corales solitarios, briozoarios y microforaminíferos bentónicos (facies 12). Hacia la rampa externa-cuenca ocurrió el depósito de capas de lutita negra de la facies 2 (Figura 10b).

Después del Capitaneano, edad determinada a partir de los fusulínidos presentes en la facies 12 , ocurrió un aumento en el influjo de a) Wordinano

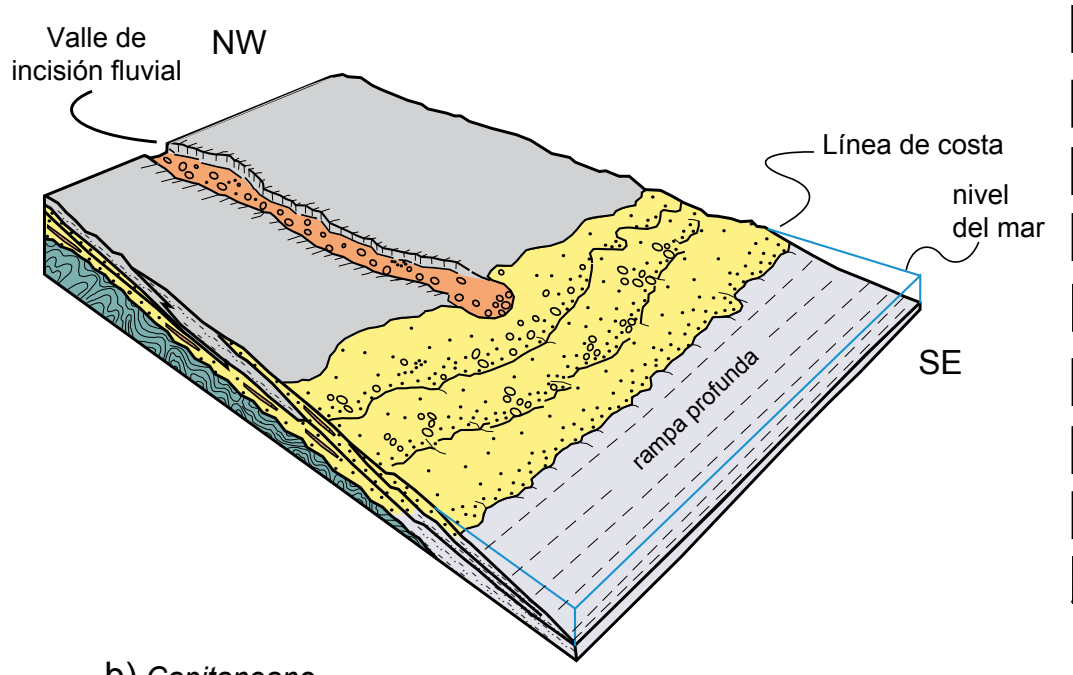

\section{Simbología}

$\because$ Conglomerado polimíctico con estratificación cruzada (fluvial)

Arenisca conglomerática (fluvial)

Lutita marina laminada

Lutita marina (expuesta)

Grainstone de crinoideos, briozoarios y braquiópodos

Packstone de braquiópodos arcilloso

Wackestone de fusulínidos

Bioherma de algas rojas coralináceas

Complejo Acatlán

b) Capitaneano

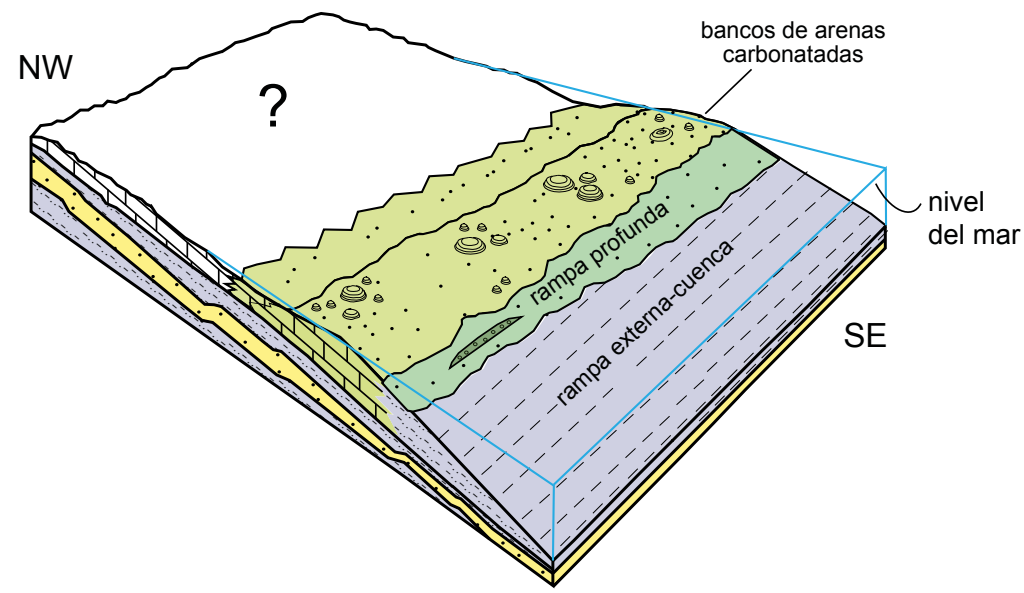

Figura 10. Modelo de sedimentación para la Formación Olinalá. (a) En el esquema se muestra la distribución idealizada de facies terrígeno-carbonatadas en este sistema de rampa durante un periodo de nivel del mar bajo en el Wordiano. Se ilustra cómo los sistemas fluviales formaron un valle de incisión al erosionar los depósitos de rampa cuando parte de la plataforma quedó expuesta. (b) Distribución inferida de las facies de bancos de arena carbonatada, rampa profunda y rampa externa en un periodo de nivel del mar alto durante el Capitaneano. La facies de grainstone de crinoides, briozoarios y braquiópodos formó grandes bancos de arena carbonatada que se extendieron de manera continua a través de varias decenas de metros. En este trabajo no se reconocieron rasgos estratigráficos, sedimentológicos o petrográficos que indiquen la presencia de facies lagunares en esta formación. 
detritos que disminuyó drásticamente la diversidad y productividad de la fábrica de carbonatos hasta que terminó con la misma. Este evento es registrado por un abrupto cambio de facies de bancos de arena carbonatada a facies de lutita negra de rampa externa que está registrado en la parte superior de la Formación Olinalá (Figura 2). En este episodio se depositaron una gran cantidad de sedimentos pelíticos con delgados niveles calcáreos donde se acumularon abundantes amonoideos (facies 2).

\section{Edades U-Pb en circón y edad máxima de depósito de la base de la Formación Olinalá}

La edad máxima de depósito (MDA, del inglés: maximum depositional age) calculada para la base de esta sucesión sedimentaria es de $268 \pm 5 \mathrm{Ma}$ (Wordiano); los errores analíticos asociados al conjunto de granos utilizados para obtener dicha edad se calcularon por la media cuadrática de las desviaciones ponderadas (MSWD, del inglés: mean square of weighted deviates) y corresponde a una MSWD $=1.4$, basada en cinco granos $(n=5)$. La MDA es consistente con la edad determinada a partir de amonoideos colectados cerca de la base de la formación (e.g., Vachard et al., 1993; González-Arreola et al., 1994). La consistencia entre ambas edades sugiere que la edad máxima de depósito calculada es aproximada a la edad de depósito de la base de la Formación Olinalá.

Las edades $\mathrm{U}-\mathrm{Pb}$ obtenidas de granos de circón detrítico de la Formación Olinalá resultan en este momento una herramienta limitada para proponer sólidas hipótesis de procedencia debido a que estas firmas de edad son similares a las de muchas fuentes diferentes en México, como es discutido por Martini et al. (2020). Particularmente, el $70 \%$ de las edades U-Pb obtenidas para esta formación corresponden al Mesoproterozoico medio-Neoproterozoico temprano (Figura 9), mismas que son comunes en rocas de los basamentos cristalinos paleozoicos y precámbricos del sur de México (e.g., el complejo Ayú, Talavera-Mendoza et al., 2005; el complejo Oaxaqueño, Solari et al., 2014;). Como es ilustrado por Martini et al., (2020), la discriminación de los distintos basamentos como áreas fuente puede hacerse si, aunado a edades $\mathrm{U}-\mathrm{Pb}$ en circón, se analizan modas detríticas y se determina la química de minerales pesados diagnósticos. Por lo anterior, elucidar la procedencia e historia de dispersión de sedimentos para la Formación Olinalá es un tema importante que puede ser abordado en futuras investigaciones.

\section{CONCLUSIONES}

Esta sucesión sedimentaria está constituida por una amplia diversidad de facies terrígenas continentales y marinas, así como por facies carbonatadas marinas. La arquitectura estratigráfica es indicativa de un sistema de depósito de plataforma tipo rampa homoclinal desarrollada en aguas cálidas bajo condiciones marinas normales. El análisis de facies también permitió reconocer un prominente sistema fluvial que erosionó parte de la plataforma marina y formó un valle de incisión fluvial de al menos $130 \mathrm{~m}$ de profundidad.

El análisis $\mathrm{U}-\mathrm{Pb}$ en granos de circón detrítico obtenidos de dos muestras colectadas en la base de la Formación Olinalá permitió determinar una edad máxima de depósito de $268 \pm 5 \mathrm{Ma}$ (Wordiano), misma que es consistente con la edad bioestratigráfica previamente determinada para la base de esta unidad, por lo que se deduce que la edad geocronológica obtenida en este trabajo es aproximada a la edad de depósito de la base de esta formación. El registro estratigráfico de esta sucesión sedimentaria pérmica permite deducir variaciones en el nivel del mar de distinta magnitud que controlaron en parte su evolución sedimentaria.

\section{MATERIAL SUPLEMENTARIO}

La Tabla DR-1 del suplemento electrónico se puede decargar en el portal web de la Revista <www.rmcg.unam.mx $>$, dentro de la versión html del resumen de este artículo.

\section{AGRADECIMIENTOS}

Agradecemos a Gustavo Tolson Jones del Instituto de Geología de la Universidad Nacional Autónoma de México (UNAM) y a las autoridades del Instituto Mexicano del Petróleo (IMP), por el apoyo logístico y financiero para el desarrollo de este estudio. El primer autor agradece al CONACyT por la beca otorgada para realizar sus estudios de maestría. Agradecemos también a Luigi Solari (Centro de Geociencias) por los puntos finos en geocronología U-Pb. A Francisco Sour Tovar y Sara Quiroz Barroso (Facultad de Ciencias, UNAM) por la identificación de los invertebrados fósiles colectados. A Juan Antonio Flores de Dios, Elisa Fitz Díaz y Antonio Pola Villaseñor por el apoyo en el trabajo de campo. Agradecemos también a Carlos Ortega-Obregón por proporcionar asistencia técnica en el Laboratorio de Estudios Isotópicos (LEI) del Centro de Geociencias, UNAM, y por la reducción de datos isotópicos. A Yam Zul Ocampo-Díaz por su ayuda en la edición de la Figura 5. El manuscrito se benefició enormemente de las sugerencias de Michelangelo Martini y un revisor anónimo. Al Lic. Luis Casiano Casiano de la Biblioteca Conjunta en Ciencias de la Tierra (BCCT, UNAM) por los servicios bibliotecarios prestados.

\section{REFERENCIAS}

Adey, W.H., Macintyre, I.G., 1973, Crustose coralline algae: A re-evaluation in the geological sciences: Geological Society of America Bulletin, 84(3), 883-904.

Ahr, W., 1985, Limestone depositional sequences on shelves and ramps: modern and ancient: Geology Today, May-June, 84-89.

Allen, J.R.L., 1970, Studies in fluviatile sedimentation: a comparison of fining upwards cyclothems, with particular reference to coarse member composition and interpretation: Journal of Sedimentary Petrology, 40, 298-323.

Álvaro, J.J., Aretz, M., Boulvain, F., Munnecke, A., Vachard, D., Vennin, E., 2007, Fabric transitions from shell accumulations to reefs: an introduction with Palaeozoic examples: Geological Society, London, Special Publications, 275(1), 1-16.

Benan, C.A.A., Deynoux, M., 1998, Facies analysis and sequence stratigraphy of neoproterozoic Platform deposits, in Adrar of Mauritania, Taoudeni basin, West Africa: Geologische Rundschau, 87, 283-302.

Boggs, S. Jr., 1995, Principles of sedimentology and stratigraphy: New Jersey, Prentice Hall, 576 pp.

Buatois, L.A., Netto, R.G., Mángano, M.G., 2001, Reinterpretación paleoambiental de la Formación Rio Bonito (Pérmico de la Cuenca de Paraná) en el yacimiento de carbón de Iruí, Rio Grande do Sul, Brasil: integración de análisis de facies, icnología y estratigrafía secuencial de alta resolución: Geogaceta, 29, 26-28.

Buitrón, B.E., López-López, B., Flores de Dios-González A., Silva-Pineda, A., 1997, Estudio biométrico de Paranorella imperialis Cloud, 1944 (Brachiopoda-Rhynchonellida) del Pérmico de Olinalá, Guerrero, en II Convención sobre la evolución geológica de México y sus recursos asociados: Pachuca, Hidalgo, México, Universidad Autónoma del Estado de Hidalgo, Instituto de Investigaciones en Ciencias de la Tierra, Universidad Nacional Autónoma de México, Instituto de Geología, Resúmenes (Sesiones temáticas), p. 7.

Buitrón, B.E., Silva-Pineda, A., Flores de Dios, A., Vachard, D., 2005, New Permian Macrofauna and Macroflora from the Olinalá region, Guerrero State, Mexico: Annales de la Société Géologique du Nord, 11 (2eme série), 169-176. 
Burchette, T.P., Wright, V.P., 1992, Carbonate ramp depositional systems: Sedimentary Geology, 79, 3-57.

Burton, B.R., Link, P.K., 1991, Ichnology of fine-grained mixed carbonatesiliciclastic turbidites, Wood River Formation, Pennsylvanian-Permian, Souht-Central Idaho: Palaios, 6, 291-301.

Campa, M.F., Coney, P.J., 1983, Tectono-stratigraphic terranes and mineral resources distributions of Mexico: Canadian Journal of Earth Sciences, 20, 1040-1051.

Campa, M.F., García-Díaz, J.L., Bustamante-García., J., Torreblanca-Castro, T.J., Aguilera-Martínez, M.A., Vergara-Martínez, A., 1998, Carta GeológicoMinera Chilpancingo E14-8 escala 1:250,000 estados de Guerrero, Oaxaca y Puebla: Pachuca, Hidalgo, Servicio Geológico Mexicano, un mapa.

Campa, M.F., García-Díaz, J.L., Iriondo, A., 2004, El arco volcánico-sedimentario del Jurásico Medio (Grupo Tecocoyunca y Las Lluvias) de Olinalá, Guerrero, en Reunión Annual de la Unión Geofísica Mexicana: Puerto Vallarta, Jal., México, resumen, GEOS 24(2), p. 174.

Cohen, K.M., Finney, S.C., Gibbard, P.L. Fan, J.-X., 2013 (updated), The ICS International Chronostratigraphic Chart: Episodes, 36, 199-204

Coleman, J.M., 1982, Deltas, processes of deposition and models for exploration: Boston, International Human Resources Development Corporation, $124 \mathrm{pp}$.

Coleman, J.M., Prior, D.B., 1980, Deltaic sand bodies: A 1980 short course, Education course note series \# 15: Tulsa, American Association of Petroleum Geologists, 171 pp.

Collinson, J.D., 1996, Alluvial sediments, en Reading, H.G. (ed.), Sedimentary Environments: Processes, Facies and Stratigraphy: Oxford, Blackwell Science, 37-82.

Collinson, J.D., Mountney, N., Thompson, D.B., 2006. Sedimentary Structures, 3rd ed: Lóndres, Terra Publishing, , 207 pp.

Corona-Esquivel, R., 1983, Estratigrafía de la región de Olinalá-Tecocoyunca, Noreste del Estado de Guerrero: Universidad Nacional Autónoma de México, Revista del Instituto de Geología, 5(1), 17-24.

Corona-Esquivel, R.J., 1982, Pérmico marino en la región de Cualac, noreste del estado de Guerrero, México: México, D.F., Consejo de Recursos Minerales, Exploración Zona Sur, Archivo Técnico 120314, documento no paginado.

Dunham, R.J., 1962, Classification of carbonate rocks according to depositional texture, en Ham, W.E. (ed.), Classification of carbonate rocks, A symposium: American Association of Petroleum Geologists Memoir, 1, 108-171.

Erben, H.K., 1956, El Jurásico Medio y el Caloviano de México, en XX Congreso Geológico Internacional: México, D.F., Monografía, 140 pp.

Esquivel-Macías, C., Solís-Marín, F., Buitrón, B.E., 2004, Nuevos registros de placas columnares de crinoides (Echinodermata, Crinoidea) del Paleozoico Superior de México, algunas implicaciones paleobiogeográficas y paleoambientales: Coloquios de Paleontología, 54, 15-23.

Fedo, C.M., Sircome, K., Rainbird, R.H., 2003, Detrital zircon analysis of the sedimentary record, en Hanchar, J.M., Hoskin, W.O. (eds.), Zircon, Reviews in Mineralogy and Geochemistry: Washington DC, Mineralogical Society of America, 53, 277-303.

Flores de Dios, A., Buitrón, B.E., 1982, Revisión y aportes a la estratigrafía de la Montaña de Guerrero: Universidad Autónoma de Guerrero, Serie Técnico Científica, (12), 3-28.

Flores de Dios, A., Vachard, D., Buitrón, B.E., 2000, The late Permian sedimentary cover (Olinalá, Ihualtepec and Yododeñe Fms.) of the Zapoteco and Mixteco terranes, Mexico: sedimentological and paleogeographic interpretations: en Research Conference on Permo-Carboniferus Platform and reefs: Society for Sedimentary Geology-IAS, p. 65.

Flügel, E., 2004, Microfacies of carbonate rocks analysis, interpretation and application: Berlin, Springer-Verlag Berlin Heidelberg, 976 pp.

Folk, R.L., 1974. Petrology of Sedimentary Rocks: Austin, second ed: Texas, Hemphill Publishing Company, 182 pp.

García-Díaz, J.L., 2004, Etude geologique de la Sierra Madre del Sur aux environs de Chilpancingo et D'Olinala, Gro.: Une contribution a la connaissance de levolution geodynamique de la marge Pacifique du Mexique depuis le Jurassique: Chambéry, Francia, Université de Savoie, tesis doctoral, 160 pp.

Ghazi, S., Mountney, N.P., 2009, Facies and architectural element analysis of a meandering fluvial succession: The Permian Warchha Sandstone, Salt Range, Pakistan: Sedimentary Geology, 221, 99-126.

González-Arreola, C., Villaseñor-Martínez, A.B., Corona-Esquivel, R., 1994, Permian fauna of the Los Arcos Formation, Municipality of Olinalá,
State of Guerrero, Mexico: Revista Mexicana de Ciencias Geológicas, 11(2), 214-221

Gutiérrez-Quinto, M.P., 2002, Análisis de facies y microfacies del miembro carbonatado de la formación Olinalá (Pérmico), Edo. De Guerrero: Taxco, Guerrero, México, Universidad Autónoma de Guerrero, Escuela Regional de Ciencias de Tierra, tesis profesional, 109 pp.

Guzmán, E.J., 1950, Geología del noreste de Guerrero: Boletín de la Asociación Mexicana de Geólogos Petroleros, 2(2), 95-156.

Jiménez-Rentería, J., Rueda-Gaxiola, J., 2002, Reestructuración formal de los grupos Consuelo y Tecocoyunca (sensu Jorge Jiménez-Rentería), con base en el estudio palinoestratigráfico de las formaciones Conglomerado prieto y Conglomerado Cualac de la Cañada de Rosario Nuevo, Tezoatlán, Oaxaca (resumen), en Tercera Reunión Nacional de Ciencias de la Tierra, Puerto Vallarta, Jalisco, México: GEOS, Unión Geofísica Mexicana, Resúmenes y Programa, p. 166.

Johnson, H.D., Baldwin, C.T., 1996, Shallow clastic seas, en Reading, H.G. (ed.) Sedimentary Environments: Processes, Facies and Stratigraphy: Oxford Blackwell Science, 232-280.

Kelley, V.C., 1971, Geology of the Pecos country, southeastern New Mexico: Socorro, Nuevo Mexico, New Mexico Bureau of Mines \& Mineral Resources, Memoir 24, p. 78.

Kerans, C., Lucia, F.J., Senger, R.K., 1994, Integrated characterization of carbonate ramp reservoirs using Permian San Andres Formation outcrop analogs: Association of Petroleum Geologists Bulletin, 78(2), 181-216.

Krainer, K., 2007, Late Paleozoic reef mounds of the Carnic Alps (Austria/Italy)/ Biosconstructions de type <reef mounds $>$ dans le Paléozoïque superior des Alpes Carniques (Autriche/Italie): Geobios, 40, 625-643.

Le Cotonnec, A., Ventra, D., Hudson, S., Moscariello, A., 2020, Systematically variable geometry and architecture of incised-valley fills controlled by orbital forcing: A conceptual model from the Pennsylvanian Breathitt Group (Kentucky, USA): Sedimentology, 67, 2149-2188.

Li, W., Bhattacharya, J., Zhu, Y., Garza, D., Blankenship, E., 2011, Evaluating delta asymmetry three-dimensional facies architecture and ichnological analysis, Ferron 'Notom Delta', Capital Reef, Utah, USA: Sedimentology, 58, 478-507.

Loutit, T.S., Hardenbol, J., Vail, P.R., Baum, G.R., 1988, Condensed sections: the key to age determination and correlation of continental margin sequences, en Wilgus, C.K., Hastings, B.S., Kendall, C.G.St.C., Posamentier, H.W., Ross, C.A., Van Wagoner, J.C. (eds.), Sea-level changes: an integrated approach: Society of Economic Paleontologists and Mineralogists, Special Publication 42, 183-213.

Ludwig, K.R., 2008, Isoplot/Ex 3.6: A Geochronologic Toolkit for Microsoft Excel: Berkeley Geochronology Center Special Publication 4, 77 pp.

Lugli, S., Reimold, W.U., Koeberl, C., 2005, Silicified Cone-in-Cone Structures from Erfoud (Morocco): A Comparison with Impact-Generated Shatter Cones, en Koeberl, C., Henkel, H., (eds.), Impact Tectonics: Heidelberg, Springer, 81-110.

Mack, G.H., Leeder, M., Perez-Arlucea, M., Bailey, B.D.J., 2003, Sedimentology, paleontology, and sequence stratigraphy of Early Permian estuarine deposits, south-central New Mexico, USA: Palaios, 18, 403-420.

Malinkey, J.M., Mapes, R.H., Broadhead, T.W., 1986, New Late Palaeozoic Hyolitha (Mollusca) from Oklahoma and Texas, and their palaeoenvironmental significance: Palaeontology, 29(2), 303-312.

Martini, M., Solari, L., Peña-Guerrero, M., Zepeda-Martínez, M., Montomoli, C., 2020, Guidelines for assessing the provenance of Mesozoic and Cenozoic clastic succession sourced by pre-Jurassic basement complexez in southernmost North America: Journal of Sedimentary Research, 90, 513-532.

Mazzullo, S.J., 1999, Paleoenvironments, cyclicity, and diagenesis in the outer shelf Tansill Formation in the Carlsbad Embayment (Dark Canyon), Northern Guadalupe Mountains, New Mexico en Saller, A.H., Harris, P.M., Kirkland, B.L., Mazzullo, S.J. (eds.), Geologic framework of the Capitan Reef, Society for Sedimentary Geology, Special Publication 65, 107-128.

McLaughlin, P.I., Brett, C.E., Taha, S.L., Cornell, S.R., 2004, High-resolution sequence stratigraphy of a mixed carbonate-siliciclastic, cratonic ramp (Upper Ordovician; Kentucky-Ohio, USA): insights into the relative influence of eustasy and tectonics through analysis of facies gradients: Palaeogeography, Palaeoclimatology, Palaeoecology, 210, 267-294.

Miall, A.D., 2006, The geology of fluvial deposits: sedimentary facies, basin 
analysis, and petroleum geology: Italy, Springer, $582 \mathrm{pp}$.

Morán-Zenteno, D.J., Caballero-Miranda, C.I., Silva-Romo, M., OrtegaGuerrero, B., González-Torres. E., 1993, Jurassic-Cretaceous paleogeographic evolution of the northern Mixteca terrane, southern Mexico: Geofísica Internacional, 32(3), 453-473.

Morin, J., Desrochers, A., Beauchamp, B. 1994, Facies analysis of the lower Permian platform carbonates, Sverdrup basin, Canadian arctic archipielago: Facies, 31, 105-130.

Nichols, G., 2009, Sedimentology and stratigraphy: United Kingdom, WileyBlackwell, $419 \mathrm{pp}$.

Nielsen, J.K., Hanken, N.M., 2002, Late Permian carbonate concretions in the marine siliciclastic sediments of the Ravnefjeld Formation, East Greenland: Geology of Greenland Survey Bulletin, 191, 126-132.

Olariu, C., Bhattacharya, J.P., 2006, Terminal distributary channels and delta front architecture of river-dominated delta systems: Journal of Sedimentary Research, 76, 212-233.

Ortega-Gutiérrez, F., Elías-Herrera, M., Reyes-Salas, M., Macías-Romero, C., López, R., 1999, Late Ordovician-Early Silurian continental collisional orogeny in Southern Mexico and its Bearing on Gondwana-Laurentia connections: Geology, 27(8), 719-722.

Paton, C., Woodhead, J.D., Hellstrom, J.C., Hergt, J.M., Greig, A., Maas, R., 2010, Improved laser ablation U-Pb zircon geochronology through robust downhole fractionation correction: Geochemistry, Geophysics, Geosystems, 11(3), 1-36.

Petrus, J.A., Kamber, B.S., 2012, Vizual Age: a novel approach to laser ablation ICP-MS U-Pb geochronology data reduction: Geostandards and Geoanalytical Research, 36, 247-270.

Pemberton, S.G., Spila, M., Pulham, A.J., Saunders, T., MacEacher, J.A., Robbins, D., Sinclair, I.K., 2001, Ichnology and Sedimentology of shallow to Marginal Marine Systems, Ben Nevis and Avalon Reservoir S. Jeanne d'Arc Basin: Geological Association of Canada, Short Course, Notes, 15, 343 pp.

Prothero, D.R., Schwab, F., 2014, Sedimentary Geology: An Introduction to Sedimentary rocks and stratigraphy, 3rd ed.: New York, Freeman and Company, 593 pp.

Pullen, A., Roswell, J., Pecha, M., Gehrels, G., 2011, Rock crushing and water table instruction manual (en línea), en Arizona LaserChron Center: Departament of Geosciences, University of Arizona <https://sites.google. com/a/laserchron.org/laserchron/home >, acceso libre, consulta: junio de 2016.

Quezada-Muñetón, J.M., 1970, Prospecto Huamuxtitlán, Estado de Guerrero: México, D.F., PEMEX, Informe Geológico, 561 pp.

Read, J.F., 1985, Carbonate platform facies models: American Association of Petroleum Geologists Bulletin, 69, 1-21.

Reading, H.G., Collinson, J.D., 1996, Clastic coast, en Reading, H.G. (ed.), Sedimentary Environments: Processes, Facies and Stratigraphy: Malden, Blackwell Science, 154-231.

Ross, C.A., Ross, J.R.P., 1988, Late Paleozoic Transgressive-Regressive Deposition, en C.K. Wilgus, Hastings, B.S., Kendall, C.G. St. C., Posamentier, H.W., Ross, C.A., Van Wagoner, J.C. (eds.), Sea Level Changes -An Integrated Approach: Society for Sedimentary Geology, Special Publication 42, 227-247.

Sánchez-Zavala, J.L., Centeno-García, E., Ortega-Gutiérrez, F., 1999, Review of Paleozoic stratigraphy of Mexico and its role in the Gondwana-Laurentia connections, en Ramos, V.A., Keppie, J.D., (eds.), Laurentia-Gondwana Connections before Pangea: Boulder, Colorado, Geological Society of America, Special Paper 336, 211-226.

Scholle, P.A., Scholle, D.S., 2003, A color guide to the Petrography of Carbonate Rocks: Grains, textures, porosity and diagenesis: American Association of Petroleum Geologists, Memoir 77, p. 474.

Shen, J.W., Qing, H., 2008, Calcimicrobes, microbial fabrics, and algae in Mississippian Midale Beds, Midale and Glen Ewen Pools, Williston Basin, southeastern Saskatchewan, en Summary of Investigations 2008: Saskatchewan Geology Survey, Saskatchewan Ministry of Energy and Resources, Misc. Rep. 2008-4.1, CD-ROM, v. 1, paper A-5, 10 pp.

Silva-Pineda, A., 1991, Consideraciones sobre los conjuntos paleoflorísticos de México y sus implicaciones paleoclimáticas, en Tercer Congreso Nacional de Paleontología: México, D.F., México, Sociedad Mexicana de Paleontología, Resúmenes, 64-69.

Silva-Pineda, A., Buitrón, B.E., Flores de Dios, A., 1998, Biota (continental y marina) del Pérmico de la región de Olinalá, estado de Guerrero, en
Primera Reunión Nacional de Ciencias de la Tierra: Puerto Vallarta, Jalisco, México, Unión Geofísica Mexicana, Resúmenes y Programa, 55.

Silva-Pineda, A., Buitrón-Sánchez, B.E., Flores de Dios, A., 2000, Presencia de coníferas en el Pérmico (Leonardiano) de Calnali, Hidalgo, Patlanoaya, Puebla y Olinalá, Guerrero, en 2a Reunión Nacional de Ciencias de la Tierra: Puerto Vallarta, Jalisco, México, Unión Geofísica Mexicana, Resúmenes y Programa, GEOS, 20(3), 298-299.

Silva-Pineda, A., Buitrón-Sánchez, B.E., Arellano-Gil, J., Vachard, D., Ramírez, J., 2003, Permian Continental and Marine Biota of South-Central México: A Synthesis, en Bartolini, C., Buffler, R.T., Blickwede, J. (eds.), The CircumGulf of Mexico and the Caribbean: Hydrocarbon habitats, basin formation, and plate tectonics: American Association of Petroleum Geologists, Memoir 79, 462-275.

Silver, B.A., Todd, R.G., 1969, Permian Cyclic Strata, Northern Midland and Delaware Basins, West Texas and Southeastern New Mexico: American Association of Petroleum Geologists Bulletin, 53(11), 2223-2251.

Smith, D.B., 1974, Sedimentation of Upper Artesia (Guadalupian) Cyclic shelf deposits of northern Guadalupe Mountains, New Mexico: American Association of Petroleum Geologists Bulletin, 58(9), 1699-1730.

Solari, L.A. Gómez-Tuena, A., Bernal, J.P., Pérez-Arvizu, O., Tanner, M., 2010, $\mathrm{U}-\mathrm{Pb}$ zircon geochronology with an integrated LA-ICP-MS microanalytical Workstation: Achievements in precision and accuracy: Geostandars and Geoanalytical Research, 34(1), 5-18.

Solari, L.A., Ortega-Gutiérrez, F., Elías-Herrera, M., Ortega-Obregón, C., Macías-Romo, C., Reyes-Salas, M., 2014, Detrital provenance of the Grenvillian Oaxacan Complex, southern Mexico: a zircon perspective: International Journal of Earth Sciences, 103, 1301-1315. http://dx.doi. org/10.1007/s00531-013-0938-9.

Swinbanks, D.D., Luternauer, J.L., 1987, Burrow distribution of Thalassinidean shrimp on a Fraser Delta Tidal flat, British Columbia: Journal of Paleontology, 61(2), 315-332.

Tait, D.B., Ahlen, J.L., Gordon, A., Scott, G.L., Motts, W.S., Spitler, M.E., 1962, Artesia Group of New Mexico and West Texas: American Association of Petroleum Geologists Bulletin, 46(4), 504-517.

Talavera-Mendoza, O, Ruiz, J., Gehrels, G.E., Meza-Figueroa, D.M., VegaGranillo, R., Campa-Uranga, M.F., 2005, U-Pb geochronology of the Acatlán Complex and implications for the Paleozoic paleogeography and tectonic evolution of southern Mexico: Earth and Planetary Science Letters, 235, 682-699.

Testa, V., Bosence, D.W.J., 1999, Physical and biological controls on the formation of carbonate and siliciclastic bedforms on the northeast Brazilian shelf: Sedimentology, 46 (2), 279-301.

Tinker, S.W., 1998, Shelf-to-basin facies distributions and sequence stratigraphy of a steep-rimmed carbonate margin: Capitan depositional system, McKittrick Canyon, New Mexico and Texas: Journal of Sedimentary Research, 68(6), 1146-1174.

Tsujita, C.J., 1995, Origin of concretion-hosted shell clusters in the Late Cretaceous Bearpaw Formation, Southern Alberta, Canada: Palaios, 10, 408-423.

Vachard, D., Oviedo, A., Flores de Dios, A., Malpica, R., Brunner, P., Guerrero, M., Buitrón, B.E., 1993, Barranca d'Olinala (Guerrero): une coupe de reference pour le Permien du Mexique central; etude preliminaire: Annales de la Société Géologique du Nord, 153-160.

Vachard, D., Flores de Dios, A., Buitrón, B.E., 2004, Guadalupian and Lopingian (Middle and Late Permian) deposits from Mexico and Guatemala, a review with new data: Geobios, 37, 99-115.

Vermeesch, P., 2004, How many grains are needed for a provenance study?: Earth and Planetary Science Letters, 224, 441-451.

Ward, R.F., Kendall, C.G., Harris, P.M., 1986, Upper Permian (Guadalupian) facies and their association with hydrocarbons-Permian Basin, West Texas and New Mexico: American Association of Petroleum Geologists Bulletin, 70(3), 239-262.

Zepeda-Martínez, M., Martini, M., Solari, L., 2018, A major provenance change in sandstones from the Tezoatlán basin, southern mexico, controlled by Jurassic, sinistral normal motion along the Salado River fault: Implications for the reconstruction of Pangea: Journal of South American Earth Sciences, 86, 447-460.

Manuscrito recibido: abril 13, 2020

Manuscrito corregido recibido: agosto 11, 2020

Manuscrito aceptado: agosto 15, 2020 